Hydrol. Earth Syst. Sci., 17, 1933-1949, 2013

www.hydrol-earth-syst-sci.net/17/1933/2013/

doi:10.5194/hess-17-1933-2013

(C) Author(s) 2013. CC Attribution 3.0 License.

\title{
Water storage change estimation from in situ shrinkage measurements of clay soils
}

\author{
B. te Brake ${ }^{1}$, M. J. van der Ploeg ${ }^{1}$, and G. H. de Rooij ${ }^{2}$ \\ ${ }^{1}$ Soil Physics and Land Management Group, Wageningen University, Droevendaalsesteeg 4, \\ 6708 PB Wageningen, the Netherlands \\ ${ }^{2}$ Soil Physics Department, Helmholtz Centre for Environmental Research, Theodor-Lieser-Straße 4, \\ 06120 Halle (Saale), Germany
}

Correspondence to: B. te Brake (bram.tebrake@wur.nl)

Received: 29 October 2012 - Published in Hydrol. Earth Syst. Sci. Discuss.: 21 November 2012

Revised: 2 April 2013 - Accepted: 18 April 2013 - Published: 23 May 2013

\begin{abstract}
The objective of this study is to assess the applicability of clay soil elevation change measurements to estimate soil water storage changes, using a simplified approach. We measured moisture contents in aggregates by EC-5 sensors, and in multiple aggregate and inter-aggregate spaces (bulk soil) by CS616 sensors. In a long dry period, the assumption of constant isotropic shrinkage proved invalid and a soil moisture dependant geometry factor was applied. The relative overestimation made by assuming constant isotropic shrinkage in the linear (basic) shrinkage phase was $26.4 \%$ $(17.5 \mathrm{~mm})$ for the actively shrinking layer between 0 and $60 \mathrm{~cm}$. Aggregate-scale water storage and volume change revealed a linear relation for layers $\geq 30 \mathrm{~cm}$ depth. The range of basic shrinkage in the bulk soil was limited by delayed drying of deep soil layers, and maximum water loss in the structural shrinkage phase was $40 \%$ of total water loss in the $0-60 \mathrm{~cm}$ layer, and over $60 \%$ in deeper layers. In the dry period, fitted slopes of the $\Delta V-\Delta W$ relationship ranged from 0.41 to 0.56 (EC-5) and 0.42 to 0.55 (CS616). Under a dynamic drying and wetting regime, slopes ranged from 0.21 to 0.38 (EC-5) and 0.22 to 0.36 (CS616). Alternating shrinkage and incomplete swelling resulted in limited volume change relative to water storage change. The slope of the $\Delta V-\Delta W$ relationship depended on the drying regime, measurement scale and combined effect of different soil layers. Therefore, solely relying on surface level elevation changes to infer soil water storage changes will lead to large underestimations. Recent and future developments might provide a basis for application of shrinkage relations to field situations, but in situ observations will be required to do so.
\end{abstract}

\section{Introduction}

The soil moisture status of the unsaturated zone has a major impact on terrestrial water fluxes. The amount and distribution of soil moisture determines the actual soil water storage capacity and the partitioning of precipitation into surface runoff, evaporation, transpiration, and groundwater recharge (Milly, 1994; Western et al., 1999; Robinson et al., 2008). Quantifying these water fluxes is often done through establishing the water balance of a control volume under consideration (e.g. unsaturated zone of the soil, catchment or continent). At large spatial scales, approaches like simple bucket models, often with lumped storage variables, might be satisfactory to establish the water balance (Milly and Dunne, 1994; Farmer et al., 2003). At finer spatial scales, or to study short-term water balance dynamics, a more detailed representation of variations in fluxes and state variables is required (Eagleson, 1978) and measurements of soil water content are needed for closing the water balance (Robinson et al., 2008).

Methods to quantify soil water storage at and beyond the field scale are limited. Water balance methods have limited potential to determine soil water storage, as it is even harder to determine the various fluxes into and from the soil profile. The accumulation of measurement errors can be profound (Gee and Hillel, 1988; De Vries and Simmers, 2002). In general, soil water storage is estimated from multiple soil water content measurements. Contact-based soil moisture sensors provide direct information with high frequency, but only on a very small measurement volume compared to the soil body of interest. To improve spatial coverage and 
reduce measurement errors, wireless sensors networks appear promising (Cardell-Oliver et al., 2005; Bogena et al., 2010). Optimally designing these networks for non-scientific applications still requires further work (Vereecken et al., 2008), but efforts in multiple disciplines, such as hardware technology, signal transmission, sensor data collection and data management, have resulted in significant progress in recent years (e.g. Bogena et al., 2007, 2009, 2010; Yang et al., 2010; Zhang et al., 2011). Contact-free measurements of soil moisture, such as ground based, airborne or spaceborne remote sensing techniques or hydrogeophysical measurements like ground-penetrating radar and electromagnetic induction, can also provide information on larger spatial scales. The relatively low temporal resolution and complexity of data acquisition and processing of these measurements is a drawback. Besides, radiometer-operating remote sensing techniques suffer from limited penetration depth of the electromagnetic signal, resulting in an estimation of soil moisture content from the top few centimetres of the soil only. Other applicability issues for these methods are quantification of the dielectric permittivity - soil moisture relation and surface roughness ambiguity (Huisman et al., 2003; Lievens et al., 2011). Modelling attempts to derive the soil profile water content from remotely sensed surface soil moisture measurements have only been partly successful (e.g. Arya et al., 1983; Walker et al., 2001), as factors like hydraulic parametrization, accuracy of surface soil moisture data, model simplifications and measurement frequency are often limiting factors (Vereecken et al., 2008). Also techniques to assimilate remotely sensed near-surface soil moisture observations into hydrological models require more development to explore all acquired data to its fullest (Crow and Ryu, 2009; Liu et al., 2011; Draper et al., 2012).

The lack of fully applicable measurement techniques makes it desirable to develop an alternative methodology to measure soil profile water storage and subsequently quantify subsurface fluxes more accurately. Relying on relationships between soil water content and other, more easily and accurately measurable, variables to infer soil water storage from might be a possibility to do so. It has been long recognized that surface elevation changes of expansive clay soils could serve as an estimate for soil water storage change (Yule and Ritchie, 1980a,b; Bronswijk, 1991b; Cabidoche and OzierLafontaine, 1995; Cabidoche and Voltz, 1995; Kirby et al., 2003). Water storage change in clay soils results in volume change of the soil matrix and the relation between water storage change and volume change can be accurately quantified under laboratory conditions (e.g. Stirk, 1954; Bronswijk and Evers-Vermeer, 1990; Braudeau et al., 1999; Cornelis et al., 2006), in lysimeters (e.g. Yule and Ritchie, 1980b; Bronswijk, 1991a; Mitchell and Van Genuchten, 1992) and in situ (e.g. Aitchison and Holmes, 1953; Bridge and Ross, 1984; Bronswijk, 1991b; Cabidoche and Ozier-Lafontaine, 1995; Coquet et al., 1998; Kirby et al., 2003). Measuring change in total water stored in the soil rather than the vertical distribution of soil water is an acceptable simplification for many hydrological purposes. Therefore, volume change of clayey soils is an attractive proxy for water storage change.

The shrinkage curve quantifies the relation between volume and water content of a volume under consideration. In the shrinkage curve, volume and water content are generally expressed relative to the volume of solids, resulting in dimensionless factors void ratio $e$ and moisture ratio $\vartheta$ :

$e=\frac{\text { Volume of pores }}{\text { Volume of solids }}$

$\vartheta=\frac{\text { Volume of water }}{\text { Volume of solids }}$

During shrinkage of initially saturated pure clay, the only mineral soil component that can cause shrinkage, three shrinkage phases can be distinguished. In the case of only external shrinkage, i.e. cracks do not develop in the clay, the shrinkage phases can be qualitatively described as (Haines, 1923; Bronswijk and Evers-Vermeer, 1990; Chertkov, 2007a):

- Normal shrinkage: water loss of the clay is completely compensated by volume decrease until the air entry point is reached. The clay remains saturated.

- Residual shrinkage: water loss exceeds the volume change of the clay, from the air-entry point to the shrinkage limit, at which point all water resides in isolated pockets or in films around soil particles.

- Zero shrinkage: the clay particles have reached their densest configuration. The clay volume does not decrease any further and water loss is equal to the increase of the air volume in the clay.

An additional shrinkage phase is often considered for shrinkage of aggregated soils (large samples comprising aggregates or field soils) that lose water upon first drying with limited, and often non-linear and non-constant, volume change (Stirk, 1954; Bronswijk and Evers-Vermeer, 1990; Braudeau et al., 2004; Chertkov, 2007a). Water loss in this phase might originate from a relatively rigid soil textural domain (Chertkov, 2007a), relatively stable macro- or micropores, or from simultaneous drying of stable domains or pores and shrinking of aggregates (Braudeau and Mohtar, 2006). Apart from the occurrence of a structural shrinkage phase, the shrinkage curves of pure clay and that of an aggregated soil containing the clay, differ largely as a result of inter- and intra-aggregate crack development. Factors affecting crack development are measurement volume, sample preparation, clay content and soil structure (Jayawardane and Greacen, 1987; Cornelis et al., 2006; Chertkov, 2007a,b, 2012a). As a result, the void ratio at a certain moisture ratio of an aggregated soil will always exceed the void ratio of a pure clay at that moisture ratio. The normal shrinkage phase remains 


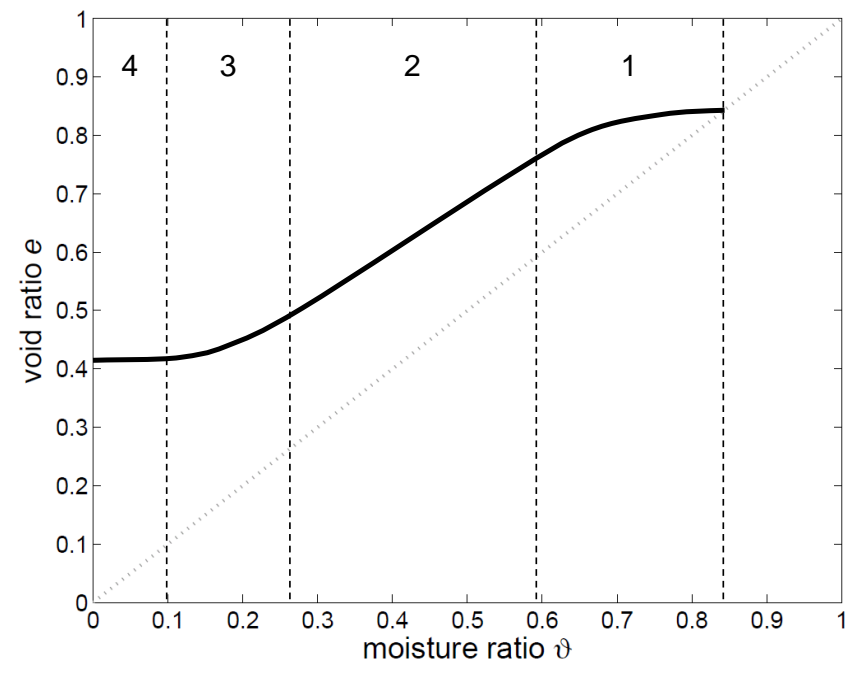

Fig. 1. Theoretical soil shrinkage curve, including 4 shrinkage phases: (1) structural shrinkage, (2) basic shrinkage, (3) residual shrinkage, (4) zero shrinkage.

characterized by a linear and constant decrease of the total volume with water loss, but water loss is essentially larger than volume decrease and shrinkage curve slopes will be less than unity (Jayawardane and Greacen, 1987; Chertkov, 2007b). Therefore basic shrinkage is preferred terminology for a phase with a linear and constant decrease of volume with water loss. Figure 1 illustrates a shrinkage curve including all four shrinkage phases.

A soil experiencing multiple drying and wetting cycles may exhibit the effect of hysteresis between swelling and shrinkage. This was observed by Peng and Horn (2007) after gradual drying and re-wetting of small cores. They distinguished two distinct parts in the swelling curve: virgin swelling at first swelling, with slopes close to one, followed by residual swelling at further wetting, where the moisture ratio increased but hardly any swelling was observed. According to Chertkov (2012b), the slope at first swelling can be larger or smaller than unity, depending on clay content, clay type and the moisture and void ratio at initial swelling. The occurrence of wetting stages during which the soil volume is not completely restored by swelling, may therefore result in an underestimation of volume change with respect to soil water storage change, and the slope of the relationship between volume change and soil water content change will be smaller than unity.

In situ measurements of the soil shrinkage curve are practically impossible to obtain, because crack volume can not be measured accurately. Therefore many authors (Aitchison and Holmes, 1953; Bronswijk, 1991b; Mitchell, 1991; Cabidoche and Ozier-Lafontaine, 1995; Coquet et al., 1998; Kirby et al., 2003) relied on layer thickness measurements to calculate volume changes. Bronswijk (1991b) provided an equation to convert vertical shrinkage measurements to soil volume changes per unit area, based on model shrinkage of a cube of clay experiencing only external shrinkage:

$\Delta V=\left[1-\left(1-\frac{\Delta z}{z}\right)^{r_{\mathrm{s}}}\right] z$,

where $\Delta V$ is the volume change of the soil matrix per unit area, $\Delta z$ is the vertical layer thickness change and $z$ is the layer thickness at saturation, all in $\mathrm{mm} . r_{\mathrm{s}}$ is the dimensionless shrinkage geometry factor (Rijniersce, 1983). In case of isotropic shrinkage, $r_{\mathrm{s}}=3$, while $1<r_{\mathrm{s}}<3$ indicates dominance of vertical shrinkage over cracking and $r_{\mathrm{s}}>3$ indicates dominance of cracking over vertical shrinkage. Bronswijk (1990) measured the shrinkage geometry of soil samples with and without overburden pressure, between two points at saturation and oven dryness. He concluded that removing overburden pressure yields $r_{\mathrm{s}}>3$, while including overburden pressure (as in a field situation) yields $r_{\mathrm{s}}=3$.

The model proposed by Bronswijk (1991b) is valid for structural and basic shrinkage and uses implicit assumptions when applied to soil layers:

1. A connected soil layer with distributed, not fully penetrating, cracks (connected soil layer) can be modelled as disconnected cubes. Therefore the distribution of volume change over thickness change and crack volume change of a connected soil layer is not influenced by horizontal stretching.

2. Cracks do not develop in drying soil samples (only external shrinkage).

3. The $r_{\mathrm{s}}$ factor does not vary with shrinkage phase and moisture content.

Chertkov et al. (2004) and Chertkov (2005) discussed the validity of these assumptions for the clay sample and soil layer case, and proposed correction factors for $r_{\mathrm{s}}$ variation with stretching, shrinkage phase, and soil moisture content, based on laboratory and in situ measurements of both vertical and horizontal shrinkage. The availability of the specific in situ data to calculate and test the applicability of these correction factors is limited, and hard to obtain.

The objective of this study is to test the applicability of the model by Bronswijk (1991b) and assumption of isotropic shrinkage at in situ overburden pressure (Bronswijk, 1990) to estimate volume change and soil water storage changes in the field from measurements of periodic vertical movement of the soil surface. We established the in situ relationship between soil water storage change from two types of contact-based sensors and soil volume change calculated from soil surface elevation changes, to test the validity of Bronswijk's simplified approach for soil layers of several depths. If this approach gives reasonable estimates of volume change of deep soil layers, we can reduce the dependence on laboratory-measured shrinkage properties and in situ horizontal shrinkage measurements. This would then allow us to 


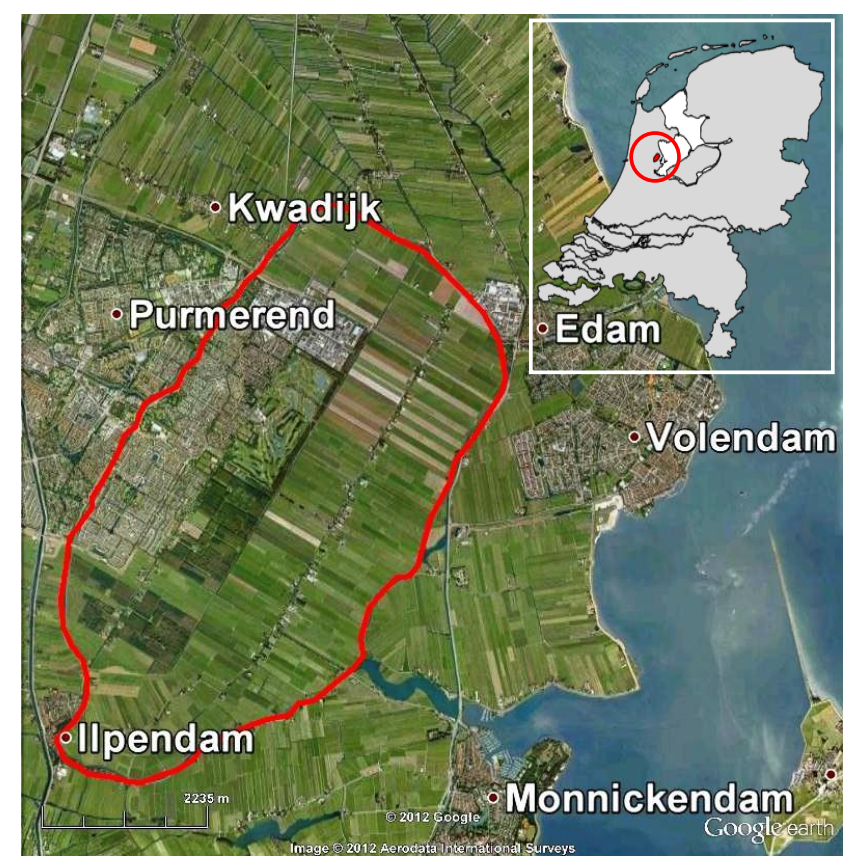

Fig. 2. Google Earth image of the measurement area.

estimate changes in water storage in the soil profile from surface level elevation measurements. This may provide a basis for upscaling soil water storage change estimates to the field or catchment scale. The effect of geometry factor $r_{\mathrm{s}}$, drying regime, measurement scale of soil moisture sensors, profile depth, and texture variations in the soil profile are assessed.

\section{Materials and methods}

\subsection{Site description}

Field measurements of soil water content and vertical shrinkage were performed in the Purmer area, approximately $15 \mathrm{~km}$ north of Amsterdam, the Netherlands. The Purmer area is a polder of $27.55 \mathrm{~km}^{2}$ with clay-rich soils of marine origin, with an elevation between 3 and $4.5 \mathrm{~m}$ below mean sea level. The area is artificially drained by three pumping stations to maintain water levels suitable for agriculture (grassland and crop rotation of mainly potatoes, maize, sugar beets, and wheat; in total $63 \%$ of the area), urban land use (22\%) and forest/parks (12\%). Open water makes up $3 \%$ of the total area. The Purmer and its location in the Netherlands are shown in Fig. 2. Measurements were performed on two adjacent fields. On field A (Kentucky Bluegrass for seed harvesting) measurements were taken from April 2010 until October 2011. On field B (sugar beets) measurements were taken between April 2010 and November 2010.

All soil layers in the upper $100 \mathrm{~cm}$ at field A were classified as loam (Soil Survey Staff, 2010). Below $100 \mathrm{~cm}$ a higher sand fraction was observed, but the exact grain size distribution was not determined. At field B the soil is clearly layered, with loam and sandy loam horizons in the upper $50 \mathrm{~cm}$ and loamy sand and sand horizons below $50 \mathrm{~cm}$ (Table 1). The clay fraction in the area consisted of $65 \%$ montmorillonite, $25 \%$ illite and $10 \%$ kaolinite minerals, as determined by X-ray diffraction.

\subsection{Swelling and shrinkage measurements}

To measure surface elevation changes resulting from clay swelling and shrinkage, ground anchors were installed based on a technique used by Bronswijk (1991b). The ground anchors consisted of metal rods with two $95 \mathrm{~mm}$-diameter discs at one end, of which one could rotate freely and one was attached to the rod. When a ground anchor was lowered in a $100 \mathrm{~mm}$-diameter auger hole it was fixed by rotating the rod, forcing both discs into the undisturbed sides of the hole. After refilling the hole, a triangular frame was placed over the rod, resting on the undisturbed soil around the refilled hole on three pins (Fig. 3). The length of the rod above the triangular frame, $L$ (see Fig. 3), was measured between marked points on the triangular frame and at the top of the rod using a $0.01 \mathrm{~mm}$-accuracy digital calliper to record the change in thickness of the layer between the anchoring depth and the soil surface. In the following, the word "layer" refers to the soil slab between the soil surface and a given anchoring depth. Slabs of soil between two ground anchors are termed "layer increments". Anchoring depths were 11, 19, 29, 56, 92 and $152 \mathrm{~cm}$ at field $A$ and 7, 19, 27, 60, 95 and $157 \mathrm{~cm}$ at field B. For convenience we will refer to the targets depths of ground anchors $(10,20,30,60,100$ and $150 \mathrm{~cm}$ at each location) instead of exact layer thicknesses in the remainder of this paper. The measurement interval was mostly 11 days but ranged between 2 and 12 days for practical reasons. Cumulative thickness changes with respect to two reference days (15 May 2010 and 12 February 2011) were calculated.

\subsection{Volume change}

Based on observations of $r_{\mathrm{s}}=3$ at in situ overburden pressure (Bronswijk, 1990), Eq. (3) was rewritten by Bronswijk (1991b) to calculate volume change of the soil matrix per unit area $(\mathrm{mm})$ by:

$\Delta V=3 \Delta z-3 \frac{\Delta z^{2}}{z}+\frac{\Delta z^{3}}{z^{2}}$.

We used Eq. (4) to convert the layer thickness changes to volume changes of the soil pedon (excluding the volume of the cracks). Values for $z$ were substituted by $z(0)$, being the layer thicknesses at the reference day (either 15 May 2010 or 12 February 2011), at which the soil was assumed to be near saturation.

Bronswijk and Evers-Vermeer (1990) estimated that Dutch clay soils, under Dutch climatic conditions, mainly experience basic shrinkage. For this situation $\Delta V$ equals water 
Table 1. Grain size distribution at several depths of soils at field A and field B.

\begin{tabular}{|c|c|c|c|c|c|c|c|c|}
\hline \multirow[b]{2}{*}{$\begin{array}{l}\text { Depth } \\
(\mathrm{cm})\end{array}$} & \multicolumn{4}{|c|}{ Field A } & \multicolumn{4}{|c|}{ Field B } \\
\hline & $\begin{array}{c}<2 \mu \mathrm{m} \\
(\%)\end{array}$ & $\begin{array}{c}2-16 \mu \mathrm{m} \\
(\%)\end{array}$ & $\begin{array}{c}16-50 \mu \mathrm{m} \\
(\%)\end{array}$ & $\begin{array}{c}>50 \mu \mathrm{m} \\
(\%)\end{array}$ & $\begin{array}{c}<2 \mu \mathrm{m} \\
(\%)\end{array}$ & $\begin{array}{c}2-16 \mu \mathrm{m} \\
(\%)\end{array}$ & $\begin{array}{c}16-50 \mu \mathrm{m} \\
(\%)\end{array}$ & $\begin{aligned}> & 50 \mu \mathrm{m} \\
& (\%)\end{aligned}$ \\
\hline $0-15$ & 19.0 & 40.1 & 20.8 & 21.1 & 19.2 & 39.1 & 22.1 & 19.6 \\
\hline $15-30$ & 18.0 & 35.1 & 23.5 & 23.4 & 15.2 & 28.4 & 23.8 & 32.6 \\
\hline $30-50$ & 19.8 & 34.8 & 22.7 & 22.7 & 15.4 & 29.5 & 21.4 & 33.7 \\
\hline $50-70$ & 18.2 & 33.9 & 21.7 & 26.2 & 5.9 & 8.9 & 9.4 & 75.8 \\
\hline 70-90 & 23.6 & 43.2 & 24.2 & 9.0 & - & - & - & - \\
\hline $90-100$ & 18.9 & 35.6 & 19.1 & 26.4 & 3.4 & 4.8 & 6.5 & 85.3 \\
\hline
\end{tabular}

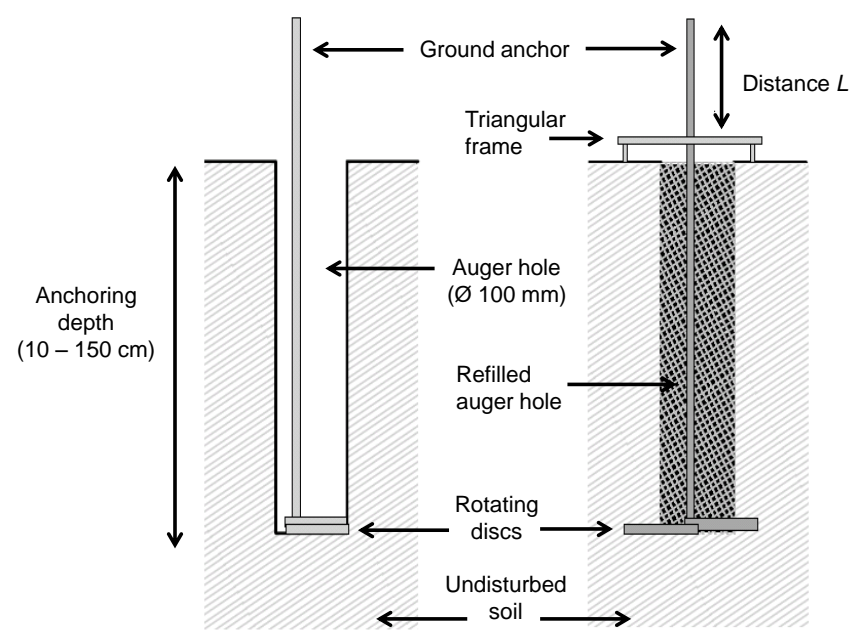

Fig. 3. Side view of the placement of ground anchors in the soil. Left: ground anchor lowered in auger hole. Right: ground anchor in refilled auger hole, with discs fixed in undisturbed soil after rotating the rod, and a metal frame placed over the rod.

storage change $\Delta W$. Including $S$ for water loss in the structural shrinkage phase (Yule and Ritchie, 1980a) yields

$\Delta W=S+\Delta V$.

\subsection{Soil moisture measurements}

Volumetric soil moisture content was measured with two contact-based sensor types: EC-5 capacitance sensors (Decagon) and CS616 water content reflectometers (Campbell Scientific). Both sensors measure the dielectric permittivity of the soil, from which volumetric moisture content is calculated. The high frequency of $70 \mathrm{MHz}$ at which both sensors are operating minimizes salinity and textural effects (Logsdon, 2009; Parsons and Bandaranayake, 2009; Francesca et al., 2010).

EC- $5 \mathrm{~s}$ have two flat, $1 \times 5 \times 56 \mathrm{~mm}$ pins spaced $5 \mathrm{~mm}$ apart, while CS616s have two $300 \mathrm{~mm}$ long rods with a diameter of $3.2 \mathrm{~mm}$, spaced $32 \mathrm{~mm}$ apart. Measurement rods of CS616s are therefore almost 5 times longer and wider apart than those of EC-5s. As the measurement volume of EC-5s is restricted to the direct surroundings of the pins (Sakaki et al., 2008; Parsons and Bandaranayake, 2009), it is far smaller than the measurement volume of the CS616s (Francesca et al., 2010).

The difference in measurement volume of the sensor types enabled us to study the relation between volume changes and soil water storage changes on two spatial scales. EC$5 \mathrm{~s}$ were assumed to measure soil water content on intraaggregate scales, while CS616s measured soil water content over a larger volume including multiple aggregates and interaggregate spaces (the bulk soil). Nine EC-5s were installed at $5,7.5,10,22.5,30,45,60,80$ and $100 \mathrm{~cm}$ depth, four CS616s at 7.5, 22.5, 45 and $80 \mathrm{~cm}$ depth. At field A, EC-5s were installed at 9 and $14 \mathrm{~cm}$ instead of 7.5 and $10 \mathrm{~cm}$, and a CS616 was installed at 9 instead of $7.5 \mathrm{~cm}$ depth. Sensors were horizontally installed in the undisturbed side of an installation pit. Their vertical alignment was slightly off so that each sensor had only undisturbed soil above and below it. The pit was carefully refilled after installation.

A custom calibration was carried out for the sensors. Soil samples were taken from the installation pits and dried and grounded to fill 5.5 L containers, with bulk densities approximating observed field soil bulk densities (between 1.26 and $1.50 \mathrm{~g} \mathrm{~cm}^{-3}$ ). The soil in the containers was saturated with water and both EC-5 and CS616 sensors were installed. The soil was then left to dry at a constant temperature of $16^{\circ} \mathrm{C}$, with continuous monitoring of raw sensor output. Containers were weighted 80 times throughout the drying period to determine volumetric water content down to $0.05 \mathrm{~cm}^{3} \mathrm{~cm}^{-3}$. Water was assumed to have a density of $1.00 \mathrm{~g} \mathrm{~cm}^{-3}$ and volume change of the clay was not taken into account. Estimated bulk density of soil clods (diameter approx. $3 \mathrm{~cm}$ ) at oven dryness ranged from 1.65 to $1.83 \mathrm{~g} \mathrm{~cm}^{-3}$. Quadratic (EC-5) and cubic (CS616) calibration equations were fitted to volumetric water content and raw sensor output. Two different calibration equations were used for CS616s for soil layers with clay content $>15 \%$ and $<15 \%$. One calibration equation was used for EC-5s.

The daily averaged soil moisture content per sensor was calculated for days at which layer thickness changes were measured. Soil water storage $W$ was calculated twice for each layer, based on only EC-5 and only CS616 data, by 
assigning the mean soil moisture content of the closest sensor to any part of the layer under consideration. Because the thickness of the layers varied due to swelling and shrinkage, and $W$ was calculated based on the initial depth $d_{i}$ assigned to sensor $i$, we accounted for layer thickness change by the ratio between the actual layer thickness $z(t)$ and the initial layer thickness $z(0), f_{\text {cor }}$ :

$W(t)=\sum_{i=1}^{n} \theta_{i}(t) d_{i} \cdot f_{\text {cor }}$

with:

$f_{\text {cor }}=\frac{z_{l}(t)-z_{l-1}(t)}{z_{l}(0)-z_{l-1}(0)}$.

In Eq. (6), $n$ is the number of sensors used to calculate $W$, $\theta_{i}$ is the volumetric water content measured by sensor $i$ and $d_{i}$ is the depth assigned to this sensor. In Eq. (7), $l$ is the layer over which to calculate $W$ and $l-1$ is the layer between surface level and the preceding ground anchor. For example, to obtain the correction factor for the layer increment $30-60 \mathrm{~cm}$, $l$ is $0-60 \mathrm{~cm}$ and $l-1$ is $0-30 \mathrm{~cm} . z_{l}$ and $z_{l-1}$ denote the actual layer thicknesses at the time indicated in parentheses. Note that for the first layer $(0-10 \mathrm{~cm}), z_{l-1}$ cancels out and $f_{\text {cor }}$ is calculated from the ratio between actual layer thickness $z_{0-10}(t)$ and the initial layer thickness $z_{0-10}(0)$ only.

By applying this correction it was ensured that water storage in each sublayer was corrected proportionally to the thickness change of that sublayer and the correction was not lumped or averaged over the total layer under consideration. Soil water storage changes were then calculated with respect to the reference days. Due to sensor failures, the EC-5s at $45 \mathrm{~cm}$ and $100 \mathrm{~cm}$ at field A and the EC-5 at $45 \mathrm{~cm}$ at field B were not used in the calculations.

\subsection{Groundwater level}

Pressure transducers recorded groundwater levels in piezometers next to the ground anchors. One piezometer was installed at each measurement location at 22 July 2010. Atmospheric pressure was measured at field A to correct the measurements by the pressure transducers in the piezometers.

\subsection{Meteorological data}

\subsubsection{Precipitation}

The rainfall rate was measured by a Parsivel disdrometer (OTT Hydrometry Ltd, extensively described by Yuter et al., 2006), located approximately $150 \mathrm{~m}$ from the measurement location at field B and $300 \mathrm{~m}$ from the measurement location at field A. The disdrometer operated from June 2010 until October 2011, but due to data logging problems, data between 7 July 2010 and 11 September 2010 were missing. Data gaps were filled with daily precipitation sums from the
Royal Netherlands Meteorological Institute (KNMI) precipitation station in Edam, located approximately $2.7 \mathrm{~km}$ northeast of the field site. Readings between the disdrometer and the precipitation station showed no systematic differences. As daily precipitation sums from KNMI stations were measured between 08:00 and 08:00 UTC, the disdrometer recordings with a frequency of one minute were summed over the same interval.

\subsubsection{Potential evapotranspiration}

Daily values of reference potential evapotranspiration between 08:00 and 08:00 UTC from the KNMI weather station in Berkhout (ca. $16 \mathrm{~km}$ north of the field site) were used. KNMI used a modified Makkink method for calculation of reference potential evapotranspiration (De Bruin, 1987; De Bruin and Lablans, 1998). Potential evapotranspiration for grass and sugar beets were calculated using crop coefficients per 10-day period provided by Feddes (1987). In the following, evapotranspiration is taken to mean potential evapotranspiration, unless stated differently.

\section{Results and discussion}

\subsection{Drying regime, soil shrinkage, and groundwater depth in 2011}

Spring 2011 was exceptionally drier, sunnier and warmer than average. KNMI reported the nation-wide averaged amount of precipitation $(49 \mathrm{~mm})$ in the months March, April and May to be the lowest in $100 \mathrm{yr}$. The total of sunshine hours $(686 \mathrm{~h})$ was the highest in $100 \mathrm{yr}$ and mean temperature $\left(11^{\circ} \mathrm{C}\right)$ was the second highest ever recorded. Figure 4 shows the effect of these exceptional weather conditions on net precipitation, soil layer thickness change, soil moisture content, and groundwater depth at field A for the 112 day period under consideration here (12 February until 3 June 2011).

The period was characterized by progressive net evapotranspiration $(P-\mathrm{ET})$ under meteorological forcing and the onset of the growing season. Total precipitation was $63.9 \mathrm{~mm}$. The precipitation event of late February had a substantial effect on cumulative $P$-ET, since the evapotranspiration rate was still small at that time (Fig. 4a). Later events were rapidly compensated by high evapotranspiration rates, resulting in total cumulative $P$-ET of $-174 \mathrm{~mm}$ at 3 June.

In February the soil was near saturation and the onset of the dry period at 28 February resulted in continuous shrinkage of all layers $(\Delta z)$ between 7 March and 3 June (Fig. 4b). The only exception was the layer $0-10 \mathrm{~cm}$ between 11 May and 23 May, where a negligible $0.02 \mathrm{~mm}$ swelling was observed. In the first interval between 12 February and 23 February no shrinkage was observed, but the layers 0$100 \mathrm{~cm}$ and $0-150 \mathrm{~cm}$ swelled up to $1 \mathrm{~mm}$. Total cumulative vertical shrinkage at 3 June in the layers $0-10,0-20,0-30$ 

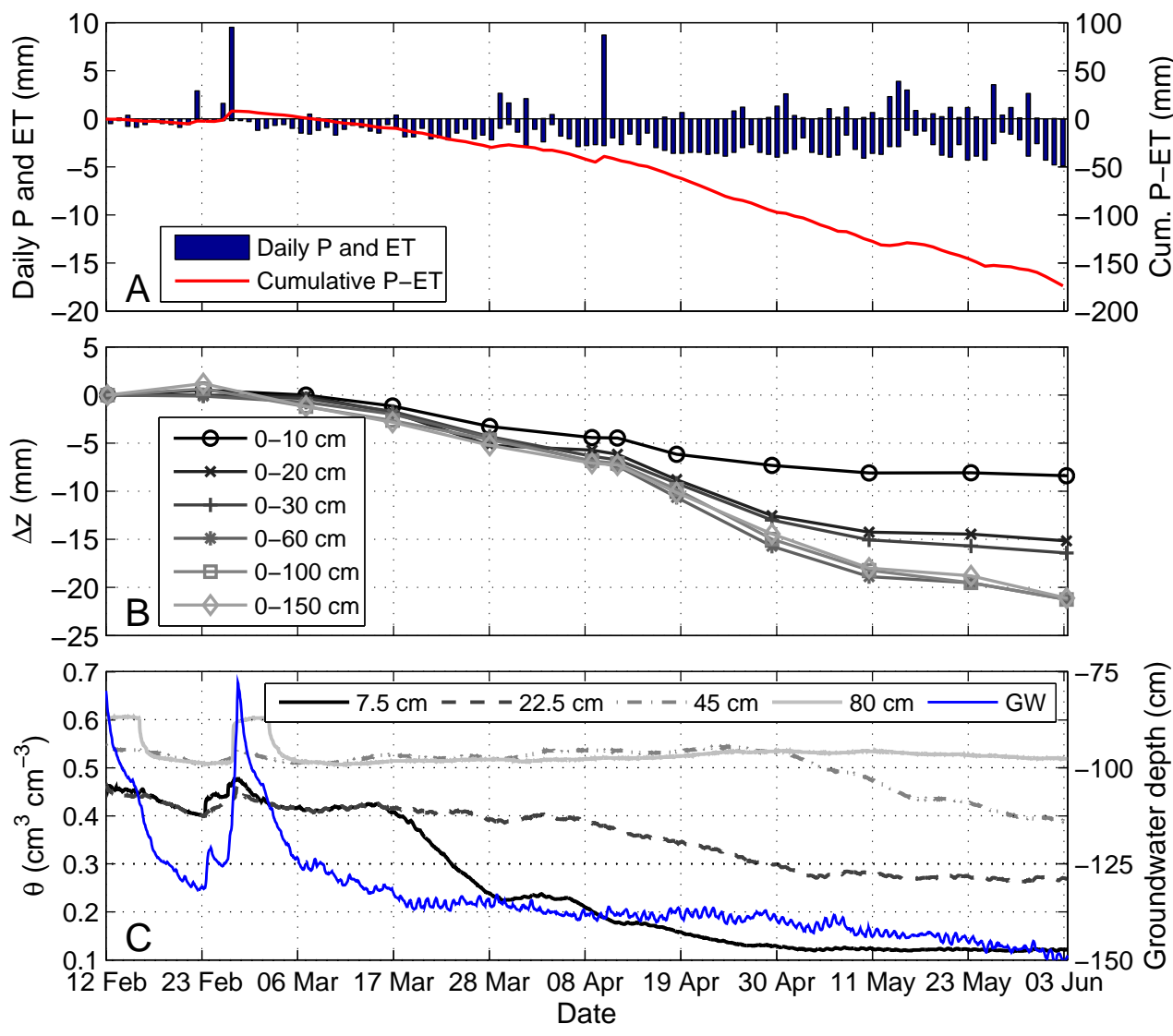

Fig. 4. Daily precipitation $P$, daily evapotranspiration ET and cumulative net precipitation $P$-ET (A), cumulative layer thickness change $\Delta z$ in six soil layers (B), volumetric soil moisture content $\theta$ from CS616 sensors at four depths, and groundwater depth (C) at field A from 12 February until 3 June 2011.

and $0-60 \mathrm{~cm}$ was $8.4,15.2,16.4$ and $21.3 \mathrm{~mm}$. Shrinkage below $60 \mathrm{~cm}$ was negligible, as evidenced from the similarity of the curves below this depth. The layer increment between 30 and $60 \mathrm{~cm}$ started contributing significantly to total shrinkage at 19 April and shrinkage almost completely originated from this layer after 30 April.

At 1 May, the start of a decrease in soil moisture content $(\theta$, CS616) at $45 \mathrm{~cm}$ depth was measured (Fig. 4c), gradually proceeding to the end of the measurement period. In the same period, $\theta$ measured by sensors installed shallower and deeper than $45 \mathrm{~cm}$ remained relatively constant. This coincided with the dominance of shrinkage in the 30 to $60 \mathrm{~cm}$ layer increment. Small amounts of precipitation after 1 May did not increase the soil moisture content and no swelling was measured.

Although the groundwater level declined from approx. $100 \mathrm{~cm}$ below surface level in early March to approx. $150 \mathrm{~cm}$ in June (Fig. 4c), moisture content at $80 \mathrm{~cm}$ did not change in this period and no additional shrinkage was observed between 60 and $150 \mathrm{~cm}$. Around the time the groundwater level peaked twice in February however, the moisture content at $80 \mathrm{~cm}$ was changing abruptly. A time lag of about
4 days was observed between the decline of the groundwater level and soil moisture content. At the start of the soil moisture decline, the groundwater level was approx. $110 \mathrm{~cm}$ below surface level, indicating that the depth of the capillary fringe above groundwater level was approx. $30 \mathrm{~cm}$. Further lowering of the groundwater table and the capillary fringe caused $0.08 \mathrm{~cm}^{3} \mathrm{~cm}^{-3}$ moisture content change. Hardly any response of the aggregate-scale soil moisture content from EC-5s to groundwater fluctuations was observed. Relatively large pores emptied, while the soil matrix retained water. The observation of the depth and water content of the capillary fringe was used to correct water storage changes.

\subsection{Volume change and soil water storage change during extensive drying}

Figure 5 shows volume change $\Delta V$ calculated from Eq. (4) and soil water storage change $\Delta W$ from the two moisture content sensor types in the six soil layers. For the soil layer extending from the soil surface to the capillary fringe, the $\Delta V-\Delta W$ relationship represents a soil profile scale shrinkage curve. A linear relation $(\Delta V=a \Delta W+b)$ was fitted 

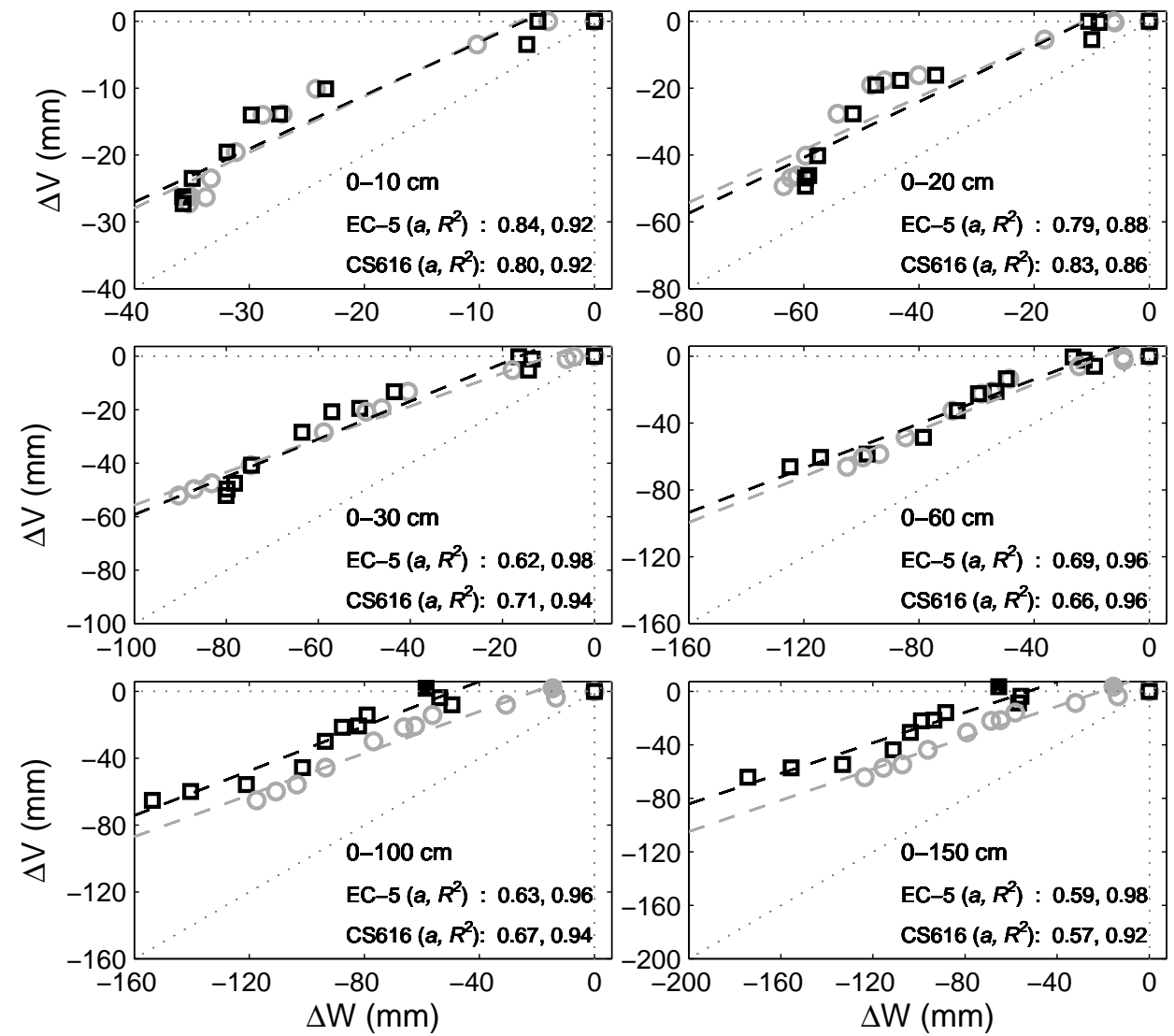

$\bigcirc$ EC-5 shrinkage $\square \quad$ CS616 shrinkage $\bigcirc \quad$ EC-5 swell $\square$ CS616 swell

Fig. 5. Relationship between volume change per unit area $\Delta V$ and water storage change $\Delta W$ (EC-5 and CS616) at field A in 2011, for six soil layers. Dashed lines represent linear regression fits through data points outside the structural shrinkage phase, with $a$ indicating the slope of the fit and $R^{2}$ being the goodness of fit.

through the data points representing volume change outside the structural shrinkage phase, meaning the first measurement interval was omitted, as no significant volume change was observed. According to this definition, the decrease in water storage during the first interval is water loss in the structural shrinkage phase $S$. Fitted slope $a$ indicates the deviation from normal shrinkage, while goodness of fit $R^{2}$ is a measure for the degree of basic shrinkage. Figure 5 gives $a$ and $R^{2}$, and all fitting parameters and goodness of fit $R^{2}$ are summarized in Table 2 .

Water loss in the structural shrinkage phase generally increased with depth (Table 2) and was larger for CS616 than for EC-5 measurements. This observation is consistent with the larger measurement volumes (comprising both aggregates and voids) of the CS616. The definition of structural shrinkage used here might be inaccurate for the deep layers (0-100 and 0-150 cm), in which an initial stage spanning multiple measurement intervals with small volume change but large water storage change was followed by a large range of basic shrinkage as indicated by EC-5 data. This is in agreement with definitions by Chertkov (2007a) and observations by Braudeau et al. (1999).

All fitted slopes were smaller than one, as expected for a field soil. Slopes based on the two sensor types were comparable, with a maximum difference of 0.09 in the $0-30 \mathrm{~cm}$ layer. In this layer, local slopes (slopes between two successive data points) larger than one are observed for the CS616 data (Fig. 5). Local slopes larger than one were also observed in the shallow layers $(0-10$ and $0-20 \mathrm{~cm})$, where volume change was overestimated compared to soil water storage change from both sensor types after an initial stage of considerable drying. When solely considering clay shrinkage, slopes larger than one are physically impossible. Relative overestimations of $\Delta V$ can result from an overestimation of the geometry factor $r_{\mathrm{s}}$ and therefore the assumption $r_{\mathrm{s}}=\mathrm{cst}=3$, made by applying Eq. (4) seems invalid, at least in the dry range of the upper layers. Several authors (Bronswijk, 1988; Cornelis et al., 2006; Chertkov, 2005, 2008) reported that $r_{\mathrm{s}}$ is a function of moisture content and shrinkage phase (Boivin, 2007). 
Table 2. Fitted parameters for cumulative volume change outside the structural shrinkage phase at field $\mathrm{A}$ in 2011 , where $\Delta V=a \Delta W+b$,

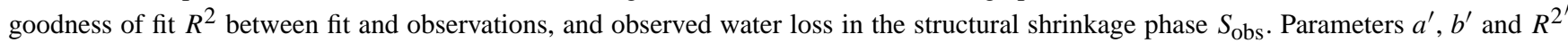
are fitted after applying $r_{\mathrm{S}}(\theta)$.

\begin{tabular}{llcrrrrrr}
\hline Sensor & Layer $(\mathrm{cm})$ & $a$ & \multicolumn{1}{c}{$b$} & $R^{2}$ & $S_{\text {obs }}(\mathrm{mm})$ & $a^{\prime}$ & $b^{\prime}$ & $R^{2^{\prime}}$ \\
\hline EC-5 & $0-10$ & 0.84 & 5.44 & 0.92 & 3.6 & 0.56 & 3.28 & 0.98 \\
& $0-20$ & 0.79 & 8.94 & 0.88 & 6.2 & 0.51 & 4.57 & 0.94 \\
& $0-30$ & 0.62 & 6.05 & 0.98 & 4.4 & 0.41 & 2.35 & 1.00 \\
& $0-60$ & 0.69 & 10.97 & 0.96 & 9.1 & 0.50 & 6.56 & 0.98 \\
& $0-100$ & 0.63 & 13.11 & 0.96 & 14.5 & 0.46 & 8.29 & 0.98 \\
& $0-150$ & 0.59 & 12.42 & 0.98 & 15.6 & 0.43 & 7.87 & 0.98 \\
\hline \multirow{2}{*}{ CS616 } & $0-10$ & 0.80 & 4.90 & 0.92 & 5.8 & 0.53 & 2.65 & 0.96 \\
& $0-20$ & 0.83 & 9.18 & 0.86 & 10.5 & 0.55 & 4.63 & 0.94 \\
& $0-30$ & 0.71 & 11.55 & 0.94 & 16.5 & 0.48 & 6.25 & 0.98 \\
& $0-60$ & 0.66 & 12.90 & 0.96 & 26.5 & 0.48 & 7.69 & 0.96 \\
& $0-100$ & 0.67 & 32.84 & 0.94 & 58.5 & 0.49 & 22.47 & 0.94 \\
& $0-150$ & 0.57 & 30.27 & 0.92 & 65.4 & 0.42 & 20.69 & 0.92 \\
\hline
\end{tabular}

Although no local slopes $>1$ were observed for layers deeper than $30 \mathrm{~cm}$, the $r_{\mathrm{s}}$ overestimation in the upper layers also led to volume change overestimation in the deeper layers. To estimate possible errors introduced by assuming $r_{\mathrm{s}}=\mathrm{cst}=3$ for deeper layers, a $r_{\mathrm{s}}$ range was linearly fitted to the observed moisture content range. A representative moisture content per measurement interval was obtained by averaging between the moisture contents at the $\Delta z$ measurement moments at the start and end of that interval. The moisture content range was 0.18 to $0.56 \mathrm{~cm}^{3} \mathrm{~cm}^{-3}$ from EC-5s and 0.12 to $0.60 \mathrm{~cm}^{3} \mathrm{~cm}^{-3}$ from CS616s. In the first interval and at maximum moisture content $r_{\mathrm{s}}$ was assumed to be 3 , while at minimum moisture content $r_{\mathrm{s}}$ equalled a critical value at which the maximum of all local slopes (over a minimum of 4 data points) was 1 . Critical $r_{\mathrm{s}}$ values were 1.57 for EC-5s and 1.38 for CS616s.

The fitted $r_{\mathrm{s}}$ values per measurement interval and per layer increment were applied to calculated volume change in each layer by using

$\Delta V_{l}=\Delta V_{l-1}+\left[1-\left(1-\frac{\Delta z_{l}-\Delta z_{l-1}}{z_{l}-z_{l-1}}\right)^{r_{\mathrm{s}} \mathrm{fit}}\right] z_{l}-z_{l-1}$

in line with Eq. (3). Here, $l$ is the layer of which to calculate $\Delta V, l-1$ is the layer between surface level and the preceding ground anchor (as in Eq. 7), and $r_{\mathrm{s}}$ fit is the fitted $r_{\mathrm{s}}$ value. Note that for the first layer $(0-10 \mathrm{~cm}), z_{l-1}$ cancels out and $\Delta V$ is calculated using Eq. (3) with $r_{\mathrm{s}}$ fit substituted.

By fitting $r_{\mathrm{s}}$ linearly to mean moisture content per layer increment and applying Eq. (8), effects of dry conditions in the upper parts of that layer were taken into account, and a realistic conservative $r_{\mathrm{s}}$ range was applied. Figure 6a and b show the results of linearly fitting $r_{\mathrm{s}}$ to EC-5 and CS616 data per layer increment, obtaining the $r_{\mathrm{s}}$ fit values applied in Eq. (8). The effect of relatively high moisture content in the capillary fringe is clearly visible for the layer increments 30-60,
60-100 and $100-150 \mathrm{~cm}$. Figure $6 \mathrm{c}$ to f illustrate how $r_{\mathrm{s}}$ fit propagated through time and depth. Figure $6 \mathrm{c}$ and d show the relationship between $\theta$ in the layer increments and the cumulative weighted average of $r_{\mathrm{s}}$ fit values over the length of the time intervals they were applied to. The obtained $r_{\mathrm{s}}$ values could be regarded as effective $r_{\mathrm{s}}$ values that could be applied in case of limited $\Delta z$ measurement moments. Figure 6e and f show the relationship between $\theta$ in the total layers and the cumulative weighted average of $r_{\mathrm{S}}$ fit values over the length of the time intervals and the layer depths they were applied to. In this case the obtained $r_{\mathrm{s}}$ values could be regarded as effective $r_{\mathrm{s}}$ values that could be applied in case of limited $\Delta z$ measurement moments and a limited number of layers defined.

Figure 7 shows the $\Delta V-\Delta W$ plot (similar to Fig. 5), after applying Eq. (8). Applied $r_{\mathrm{s}}$ range and fitting parameter per layer are summarized in Table 2. For all layers the EC-5 sensors captured soil moisture changes in aggregates that correlate with basic shrinkage, as evidenced from high $R^{2}$ values and relatively constant slopes. The CS616 sensors trended towards smaller slopes with depth for the 0-60, 0-100 and $0-150 \mathrm{~cm}$ layers, both in Fig. 5 and Fig. 7. Therefore, this can not be an effect of shrinkage geometry. In the penultimate measurement interval (between 11 May and 23 May), the volume change was only $2.3,3.3$ and $1.8 \mathrm{~mm}$ in the layers 0-60, 0-100 and 0-150 cm. At the same time soil water storage change (CS616) in these layers declined with 16.1, 19.3 and $22.3 \mathrm{~mm}$, resulting in local slopes of $0.14,0.17$ and 0.08 . The lower soil layers drained water stored in large pores to the declined groundwater (see Fig. 4c), which resulted in little shrinkage below $30 \mathrm{~cm}$ depth, but a rapid decrease in water storage. In the final measurement interval the local slopes for the layers $0-60,0-100$ and $0-150 \mathrm{~cm}$ had increased again to $0.35,0.28$ and 0.27 . The fitted slopes $a$ for the deepest soil layers resulted from zero-shrinkage of the upper part of 

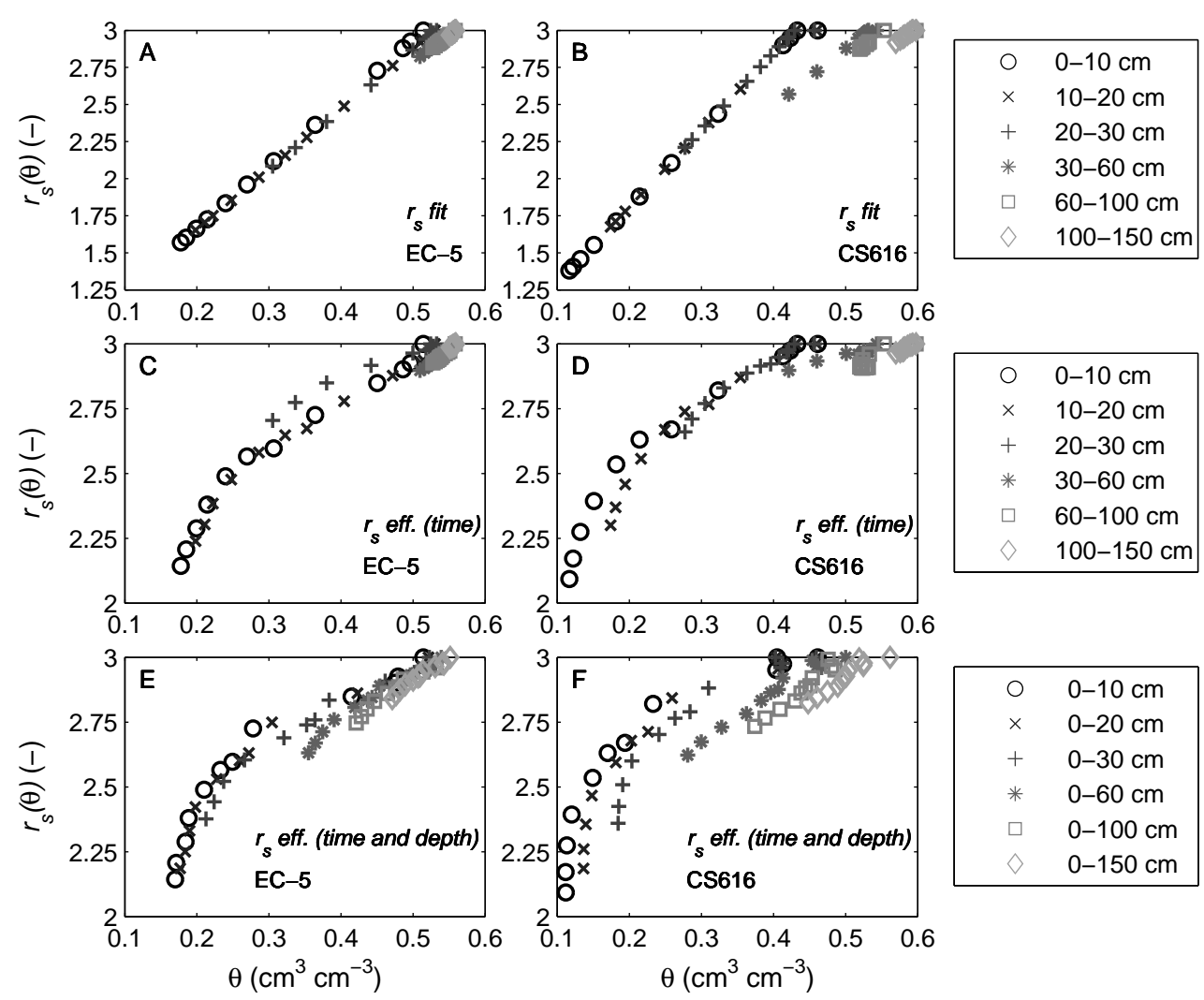

Fig. 6. Relationship between volumetric soil moisture content $\theta$ from EC-5 and CS616 and fitted $r_{\mathrm{S}}$ in layer increments (A and B), effective $r_{\mathrm{S}}$ over time in layer increments $(\mathbf{C}$ and $\mathbf{D})$, and effective $r_{\mathrm{s}}$ over time and depth of layers $(\mathbf{E}$ and $\mathbf{F})$.

the soil, structural shrinkage of the lower part and residual shrinkage in the layers in between. This was the effect of soil moisture content differences in the profile, caused by delayed drying of the lower layers and large influence of the capillary fringe. Similar findings were reported by Yule and Ritchie (1980a,b) for small and large cores. Yule and Ritchie (1980b) suggested that simultaneous water loss from multiple depths in a profile may stem from the structural and basic shrinkage phase until most of the plant-available water has been used.

The contribution of water loss in the structural shrinkage phase to the total water storage change in the profile is large. Initial water loss at structural shrinkage at the start of the measurement period $S_{\text {obs }}$ for all layers is listed in Table 2 . In the layers $0-60,0-100$ and $0-150 \mathrm{~cm}$ these amounts were amplified by water loss measured by CS616s in the two final measurement intervals. Water loss from delayed structural shrinkage was 26.9, 32.7 and $42.1 \mathrm{~mm}$ in these layers. Water loss from the combined initial and delayed structural shrinkage was therefore 53.4, 81.2 and $107.5 \mathrm{~mm}$, making up $42.8,52.8$ and $61.7 \%$ of total water loss in the layers $0-60$, $0-100$ and $0-150 \mathrm{~cm}$ over the entire measurement period.

\subsection{Effects of $r_{\mathrm{s}}$ variation on water storage change}

The effect of fitted and thereby lowered $r_{\mathrm{s}}(\theta)$ on $\Delta V$ is illustrated in Fig. 8 for the 0-20, 0-60 and 0-150 cm layers. Only $\Delta V$ based on CS616 data are shown here, since $\Delta V$ after using $r_{\mathrm{S}}(\theta)$ differed only slightly between CS616s and EC$5 \mathrm{~s}$ (Fig. 7). The maximum difference in total volume change at 3 June calculated with $r_{\mathrm{s}}=\mathrm{cst}=3$ and $r_{\mathrm{s}}(\theta)$ was 17.7, 17.5 and $15.9 \mathrm{~mm}$ for the $0-20,0-60$ and $0-150 \mathrm{~cm}$ layers. This means that applying $r_{\mathrm{s}}(\theta)$ reduced total calculated volume change by $35.8,26.4$ and $24.8 \%$ with respect to using $r_{\mathrm{s}}=\mathrm{cst}=3$. Since we are primarily interested in total soil water storage change of the unsaturated zone, and hardly any volume change occurred below $60 \mathrm{~cm}$, we can illustrate the effect of $r_{\mathrm{s}}(\theta)$ on $\Delta W$ outside the initial structural shrinkage phase for the $0-60 \mathrm{~cm}$ layer. Assuming a hypothetical slope of 0.5 for the $\Delta V-\Delta W$ relationship, the maximum overestimation of $\Delta W$ would be $35.0 \mathrm{~mm}$ when using $r_{\mathrm{s}}=\mathrm{cst}=3$, mainly stemming from the basic shrinkage phase. This would be $28.0 \%$ of total water storage change observed by CS616s in the $0-60 \mathrm{~cm}$ layer. 

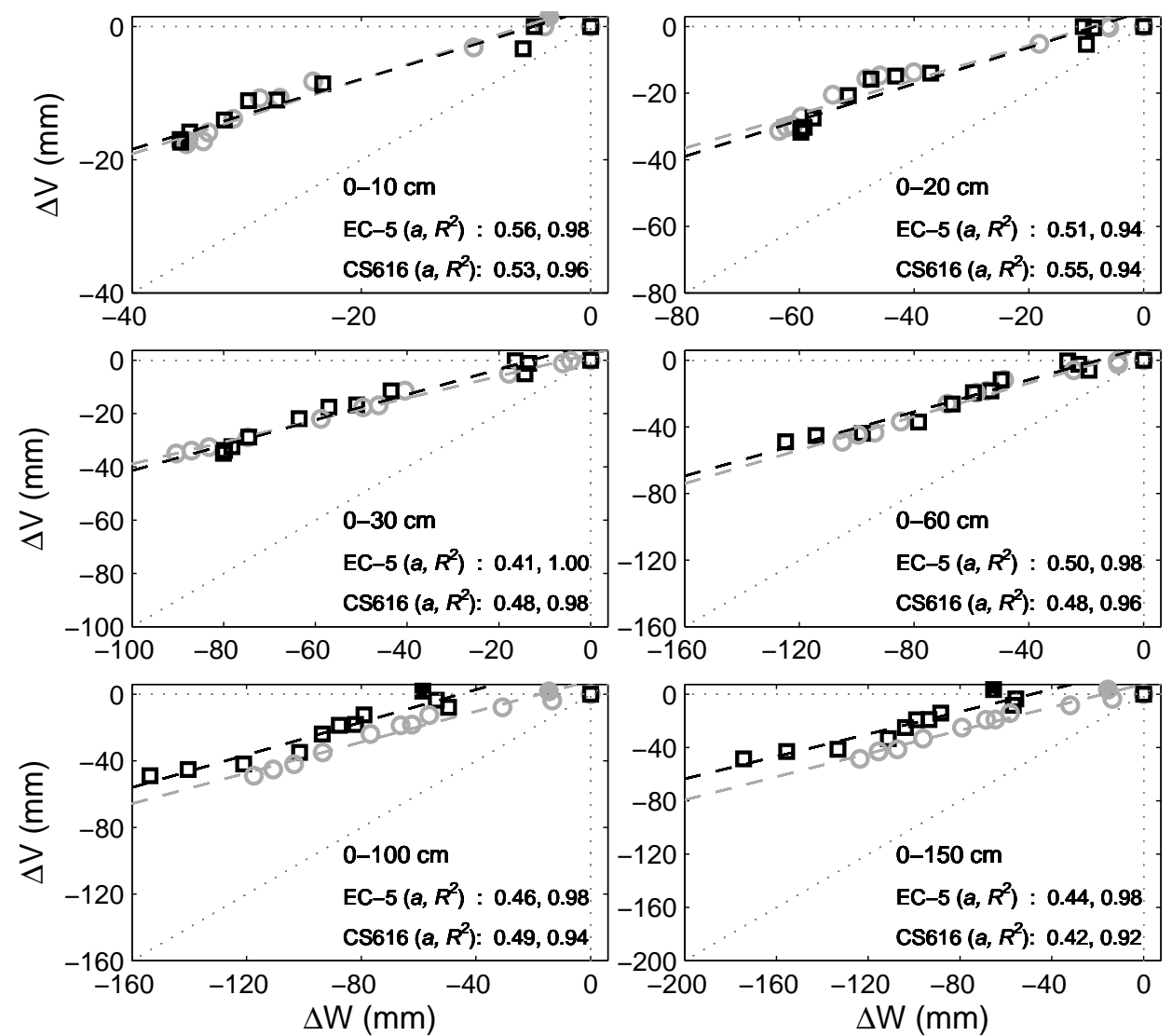

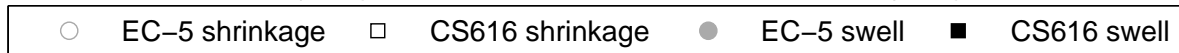

Fig. 7. As Fig. 5, but with $\Delta V$ calculated using fitted $r_{\mathrm{S}}$ factors and Eq. (8). Slope $a$ and goodness of fit $R^{2}$ per layer are indicated.

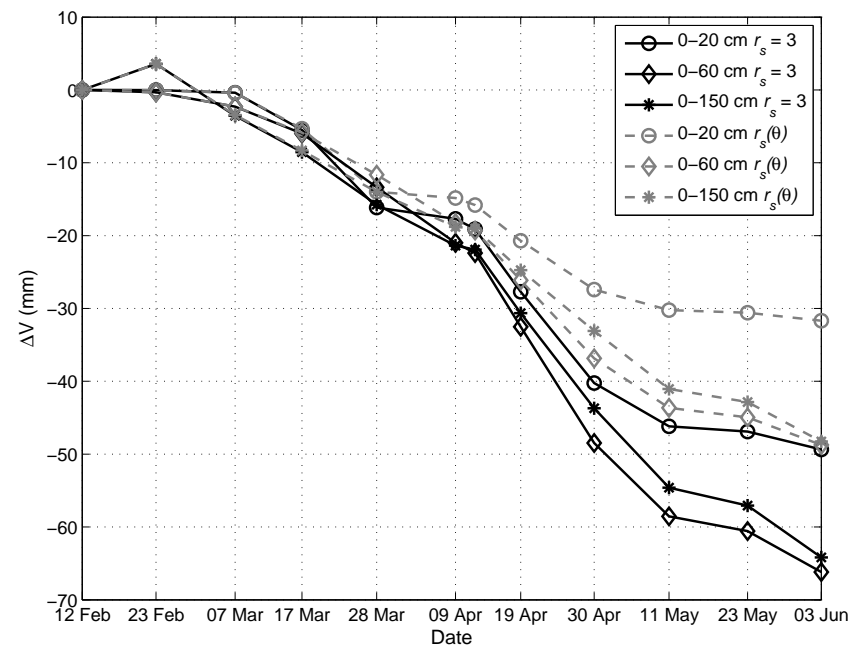

Fig. 8. Volume change $\Delta V$ at field $\mathrm{A}$ in 2011 for the layers 0 $20,0-60$ and $0-150 \mathrm{~cm}$ for isotropic shrinkage $\left(r_{\mathrm{s}}=\mathrm{cst}=3\right)$ and shrinkage geometry as function of moisture content $r_{\mathrm{S}}(\theta)$.
We assessed the minimum changes of geometry factor $r_{\mathrm{s}}$ with moisture content to prevent physically impossible slopes larger than unity. Fitted $r_{\mathrm{s}}(\theta)$ ranged from 3 to 1.38 between maximum and minimum in situ observed moisture content in the upper layers of the soil (Table 2). Further lowering of $r_{\mathrm{s}}$, resulting in lower slopes of the $\Delta V-\Delta W$ relationship, therefore seems unnecessary and unrealistic.

The fitted $r_{\mathrm{s}}$ range and its linear decrease with moisture content seem in agreement with reports by Chertkov (2008, and Fig. 4 therein). By applying maximum $r_{\mathrm{s}}=3$ an underestimation of $\Delta V$ may have been introduced, as Chertkov (2008) estimated $r_{\mathrm{s}} \gg 3$, accounting for rapid crack formation in absence of vertical shrinkage at initial drying. We did not conclusively observe an initial increase of $r_{\mathrm{s}}$, but cannot rule out that this happened either. We decided not to take this into account in the $\Delta V$ calculations and set $r_{\mathrm{s}}=3$ for the first measurement interval.

The calculated effective $r_{\mathrm{s}}$ per layer (Fig. 6e and 6f) indicate that $r_{\mathrm{s}}$ should change with moisture content, but due to its purely empirical nature it is unsure if the calculated $r_{\mathrm{s}}-$ $\theta$ relation can be transferred to other drying regimes/soils. To test this, $r_{\mathrm{s}}$ must be independently measured as function of moisture content to accurately relate $\Delta V$ and $\Delta W$ when 
applied to Bronswijk's approach of measuring surface elevation changes and calculation of volume change at the appropriate scale. Corrections as proposed by Chertkov (2005) and Chertkov (2008) might be applied, but need specific data on shrinkage curves of clay and vertical and horizontal crack volume, which are hard to obtain non-destructively.

\subsection{Drying regime, soil shrinkage, and groundwater depth in 2010}

The growing season of 2010 offered a more dynamic precipitation and evapotranspiration regime, with both dry and wet periods, and measurements were performed on a field with a lower clay content (field B). The season was characterized by two periods of progressive drying, between 15 May and 8 June and between 11 June and 5 August, and a wet period after 5 August (Fig. 9a). The periods of net drying were separated by extensive rainfall $(49.1 \mathrm{~mm})$ at 9 and 10 June, resulting in swelling measured in all layers at 15 June (Fig. 9b). The second drying period included three days with a total rainfall of $69.6 \mathrm{~mm}$ in mid-July. After 5 August, precipitation events were frequent and large, with a precipitation sum of $226 \mathrm{~mm}$ in August, while the $30 \mathrm{yr}$ mean total precipitation sum in August was $90 \mathrm{~mm}$ (KNMI).

At the start of the measurement period the soil was near saturation and soil layer thickness at the end of the measurement period was almost completely recovered to the level at the start. Between 15 June and 26 June, shrinkage of the 0$60 \mathrm{~cm}$ layer was larger than shrinkage of deeper layers. Magnitudes and patterns of thickness variations were comparable for the $0-30,0-60$ and $0-100 \mathrm{~cm}$ layers for other intervals. Most volume change originated from the upper $30 \mathrm{~cm}$ of the soil (Fig. 9b) in the early shrinkage stage.

Swelling of all layers between 0 and $100 \mathrm{~cm}$ was observed at 13 July and 18 July, caused by heavy rainfall in midJuly, but hardly any swelling of the layer $0-150 \mathrm{~cm}$ was observed. The soil moisture content increased at 7.5, 22.5 and $45 \mathrm{~cm}$ depth, while soil moisture content at $80 \mathrm{~cm}$ was stable. Thickness change due to swelling and shrinkage below $50 \mathrm{~cm}$ depth was expected to be small, because the clay content is at most $5.9 \%$ (Table 1). The apparent shrinkage of the layer $0-150 \mathrm{~cm}$ might therefore originate from subsidence of the ground anchor in the (most probably) saturated zone at $150 \mathrm{~cm}$ depth. Shrinkage of the soil above $100 \mathrm{~cm}$ after 18 July resulted in maximum total vertical shrinkage of $11.6 \mathrm{~mm}$ at 29 July, almost completely accounted for by the upper 60 $\mathrm{cm}$ of the soil.

The contribution of groundwater storage change to $\Delta W$ could not be considered for 2010, since groundwater level measurements only started at 22 July. Although the soil moisture contents did exhibit an obvious response to groundwater level variations from August to November, the moisture content of the capillary fringe could not be estimated (Fig. 9c). The layer thickness changes and slowly rising groundwater level after substantial rainfall in early August showed
Table 3. Fitted parameters for cumulative volume change outside the structural shrinkage phase at field $\mathrm{B}$ in 2010, where $\Delta V=$ $a \Delta W+b$, and goodness of fit $R^{2}$ between fit and observations.

\begin{tabular}{llcrc}
\hline Sensor & Layer $(\mathrm{cm})$ & $a$ & \multicolumn{1}{c}{$b$} & $R^{2}$ \\
\hline EC-5 & $0-10$ & 0.21 & 0.28 & 0.45 \\
& $0-20$ & 0.21 & -2.29 & 0.90 \\
& $0-30$ & 0.38 & -5.93 & 0.81 \\
& $0-60$ & 0.38 & -9.61 & 0.88 \\
& $0-100$ & 0.21 & -9.76 & 0.71 \\
& $0-150$ & 0.21 & -13.37 & 0.92 \\
\hline \multirow{2}{*}{ CS616 } & $0-10$ & 0.22 & 1.67 & 0.55 \\
& $0-20$ & 0.24 & 1.91 & 0.90 \\
& $0-30$ & 0.36 & 1.75 & 0.90 \\
& $0-60$ & 0.33 & -0.65 & 0.88 \\
& $0-100$ & 0.24 & -3.62 & 0.90 \\
& $0-150$ & 0.33 & -3.90 & 0.94 \\
\hline
\end{tabular}

that water was stored in the soil. From late August, when swelling was nearly complete and the soil was near saturation, the groundwater level reacted rapidly to precipitation. The very slow recovery of layer thickness after late August corresponds to observations of swelling curves by Peng and Horn (2007) of rapid swelling at first rewetting, followed by residual swelling at further wetting, when the moisture ratio increased but hardly any swelling was observed.

\subsection{Volume change and soil water storage change during a dynamic drying and wetting regime}

The $\Delta V-\Delta W$ relationship obtained from measurement in 2010 and application of Eq. (4) (not accounting for $r_{\mathrm{s}}$ variations with soil moisture content and swelling or shrinking stage) is shown in Fig. 10. The precipitation and evapotranspiration dynamics caused variation in soil water storage change with respect to the starting date and accompanied alternating swelling and shrinkage periods. Water loss in the structural shrinkage phase could not objectively be distinguished, due to scatter in the relation between storage change and volume change, partly caused by the residual swelling occurring from September to November. Maximum soil volume was expected to occur in the structural shrinkage phase and a linear relation $(\Delta V=a \Delta W+b)$ was fitted through all datapoints with water storage smaller than water storage at maximum volume (Fig. 10). By applying this procedure, the number of points the fit was based on varies between layers and sensors. Fitting parameters and goodness of fit $R^{2}$ are summarized in Table 3.

There was a mismatch between the response of water storage change based on EC-5s and volume change, at least at the measurement frequency and scale used here. For the 0$30 \mathrm{~cm}$ layer, swelling in the dry end of the curve for example was not accompanied by the expected increase in water storage (Fig. 10). Hysteresis between swelling and shrinkage 

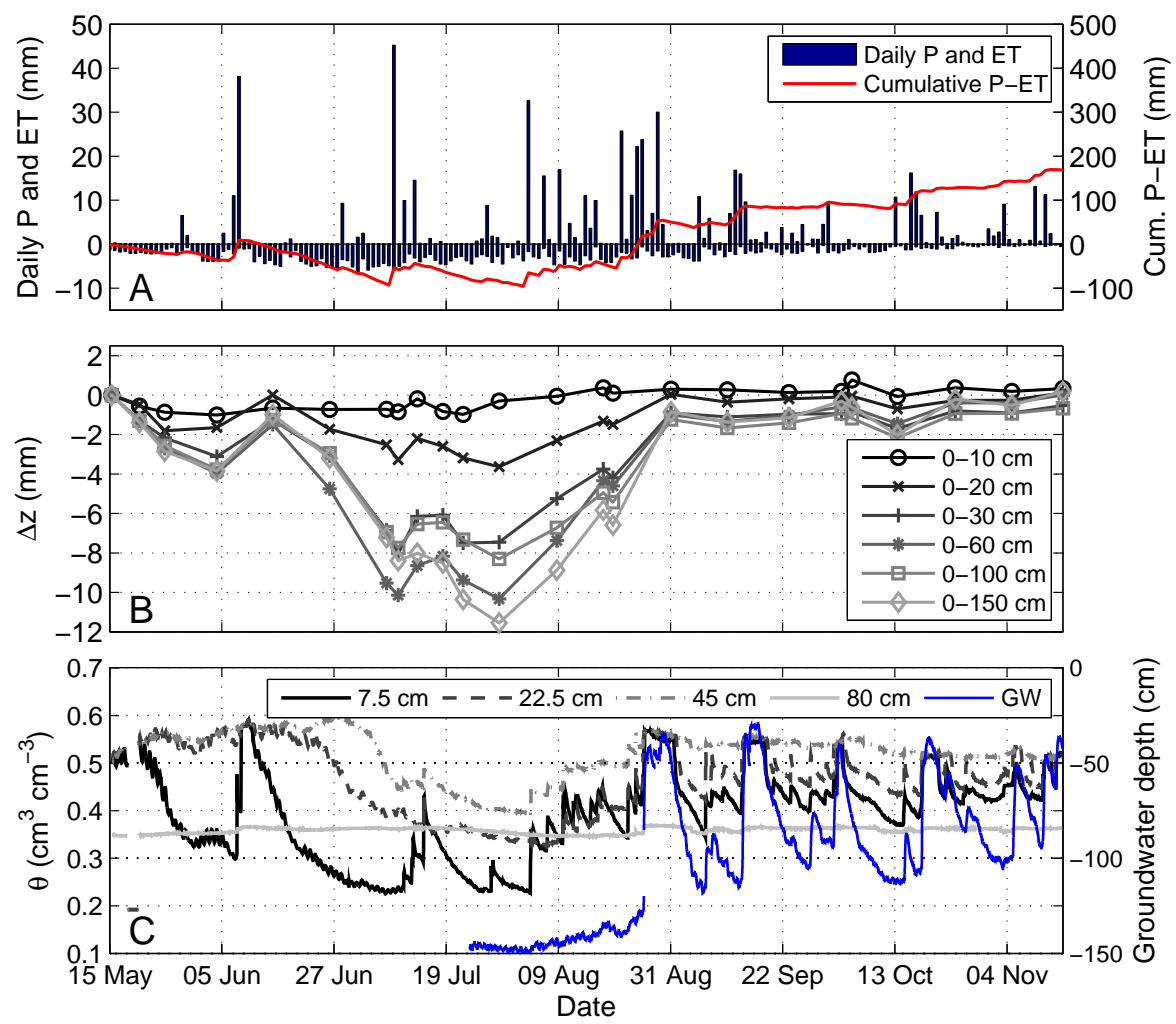

Fig. 9. Daily precipitation $P$, daily evapotranspiration ET and cumulative net precipitation $P$-ET (A), cumulative layer thickness change $\Delta z$ in six soil layers (B), volumetric soil moisture content $\theta$ from CS616 sensors at four depths and groundwater depth (C) at field B from 15 May until 15 November 2010. Note that soil moisture data logging failed between 18 May and 20 May, and groundwater level measurements started at 22 July.

was also observed by Peng and Horn (2007). Since individual swelling stages, except for the final swelling stage, did not restore the soil volume to its maximum volume and were not accompanied by expected water storage increase, net $\Delta W$ was larger than net $\Delta V$, resulting in mild slopes. The effect of variable conditions, with alternation of shrinkage and swelling, was enhanced by a difference in measurement scale of soil surface elevation change by ground anchors and soil moisture content by EC- 5 sensors. Soil water content and volume change mainly occurred in parts of the soil that were in close contact with the atmosphere (e.g. the top of the soil and inter-aggregate pores), and less from the interior of aggregates in which the EC-5s were measuring. The small measurement volumes of EC-5s were thus relatively shielded from water content changes, and not representative for the profile scale at which the volume change measurements were acquired. The measurement scale of the CS616s (including aggregates and inter-aggregate spaces) matched better with the scale of volume change measurements, resulting in less scatter for soil water storage change based on CS616 measurements, slightly higher $R^{2}$ values (Table 3), and no hysteresis in the dry range. For both sensor types $R^{2}$ for the linear fits were high, indicating a large range of basic shrinkage over the entire moisture range observed in 2010.

Soil water storage changes calculated from the CS616s were larger than those calculated from EC-5s, mainly due to water loss at limited volume change. This again suggests that water loss in the structural shrinkage phase is larger in the bulk soil scale of CS616s than in the aggregate scale of EC-5s. As a result, fitted slopes of the $\Delta V-\Delta W$ relationship again were comparable for the two sensor types, except for the layer $0-150 \mathrm{~cm}$ (which will be discussed below).

Slopes varied with depth. In the upper layers slopes were low, probably because the effect of alternating occurrence of swelling and shrinkage was largest here. This effect was less in deeper layers and the largest slopes for both soil moisture sensors were observed in the layers $0-30$ and $0-60 \mathrm{~cm}$. In the sandy layers below $50 \mathrm{~cm}$, little volume change occurred upon water storage change, resulting in small slopes in the layers $0-100$ and $0-150 \mathrm{~cm}$.

The clay content in the upper $50 \mathrm{~cm}$ was comparable to field A, but slopes were much lower, as compared to both Figs. 5 and 7. If $r_{\mathrm{s}}$ variations with moisture content would have been considered, the slopes in Fig. 10 would probably have been even lower, but applying swelling and shrinkage $r_{\mathrm{s}}$ 

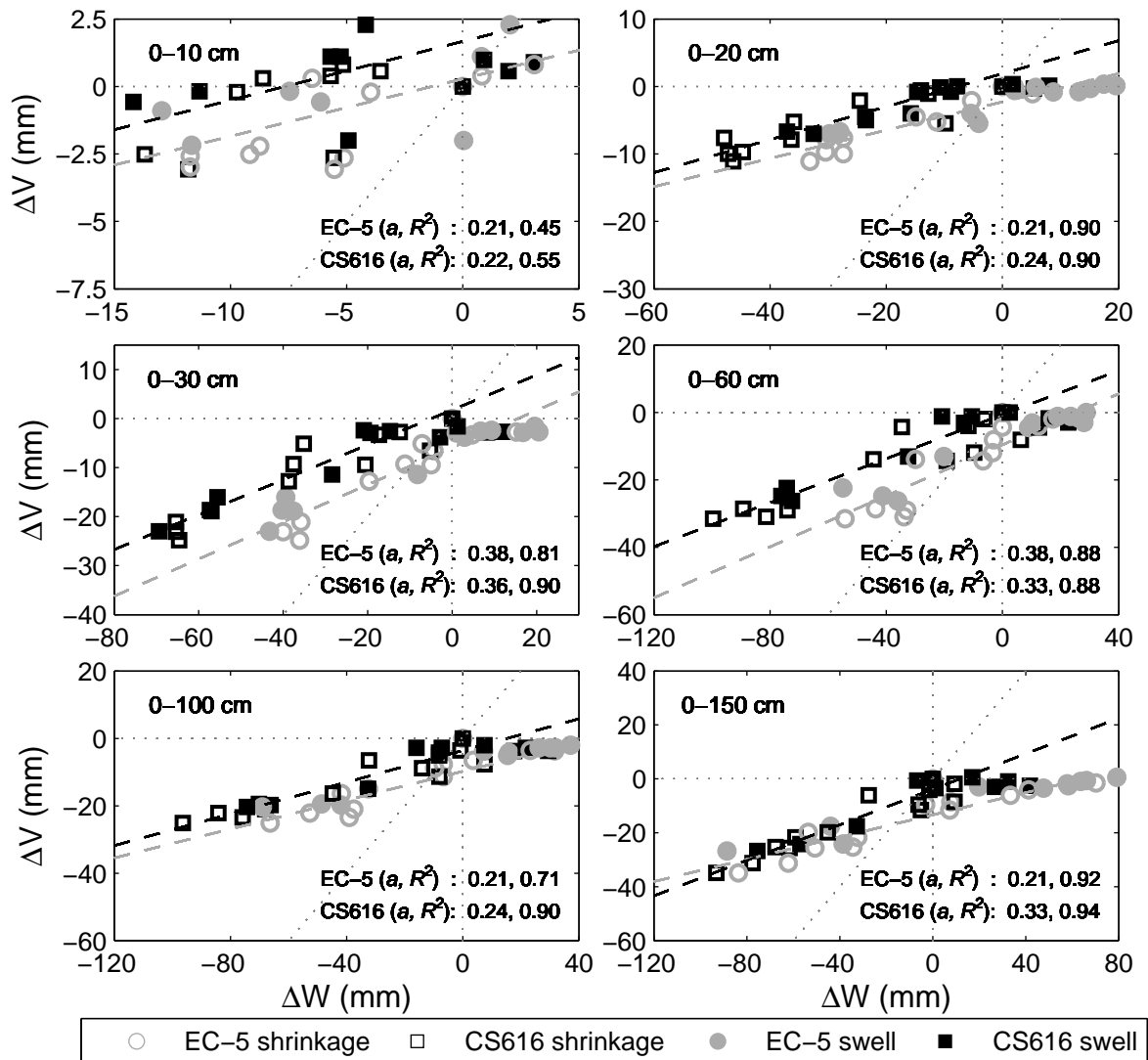

Fig. 10. Relationship between volume change per unit area $\Delta V$ and water storage change $\Delta W$ (EC-5 and CS616) at field B in 2010, for six soil layers. Dashed lines represent linear regression fits through data points outside the structural shrinkage phase, with $a$ indicating the slope of the fit and $R^{2}$ being the goodness of fit. Note the difference between the $\mathrm{x}$ - and $\mathrm{y}$-axes.

values would be highly subjective, as appropriate values are not available in literature. The mild slopes can be regarded as the net result of no shrinkage of rigid soil particles and reduced (residual or zero) shrinkage of dry surface layers of aggregates combined with basic shrinkage in the clay aggregates interiors (Yule and Ritchie, 1980a,b). The magnitude of maximum vertical shrinkage at field $A$ in 2010 was comparable to field $\mathrm{B}$ (data not shown), but the $\Delta V-\Delta W$ relationship could not be considered due to soil moisture measurements failures. The comparable clay content in both fields and the comparable observed vertical shrinkage at both fields in 2010 lead to the conclusion that the variation in shrinkage stages within a soil layer was caused and/or enhanced by the changes in weather forcing (precipitation, temperature, solar radiation) as observed in 2010 .

The relatively large slope for the $0-150 \mathrm{~cm}$ layer based on CS616 measurements compared to EC-5 measurements is striking. Since no groundwater storage change estimation could be made, water storage change in this layer was largely determined by moisture content changes in the CS616 sensor installed at $80 \mathrm{~cm}$ depth. Moisture contents measured by the EC-5 and CS616 at this depth varied only slightly in the dry periods. The EC-5 at $100 \mathrm{~cm}$, however, recorded a considerable moisture content decrease (data not shown), resulting in the relatively large water storage change based on EC5 measurements in the $0-150 \mathrm{~cm}$ layer. The CS616 sensors may have underestimated the total water storage decrease in the $0-150 \mathrm{~cm}$ layer due to limited coverage by only four sensors, thereby overestimating the slope in the $\Delta V-\Delta W$ relationship. This indicates the need for inclusion of data on groundwater and capillary fringe depth, for soil water storage change calculations. Preferred root water uptake by sugar beets from deep layers, as reported by Brown et al. (1987) and Camposeo and Rubino (2003) might be an explanation for water content changes at $100 \mathrm{~cm}$-depth.

\section{Conclusions and outlook}

Basic, linear, shrinkage is the major shrinkage phase in a clayey field soil under continuous drying, on both aggregate scale and bulk soil scale, including cracks, structural pores, and multiple aggregates. Linear shrinkage with much smaller slopes was observed in the case of a more dynamical drying regime, with variation of dry and wet periods. 
Bronswijk and Evers-Vermeer (1990) concluded that clay soils under Dutch climatic conditions experience a large degree of normal shrinkage, based on aggregate void and moisture ratios at pressure heads from 0 to $-16000 \mathrm{~cm}$. Based on observations presented here we can confirm this conclusion for field soils, although slopes of the $\Delta V-\Delta W$ relationship are much smaller than observed by Bronswijk and Evers-Vermeer. Shrinkage slopes larger than unity were observed in clayey field soils experiencing a large range of soil moisture contents, when applying the isotropic shrinkage approach from Bronswijk (1990, 1991a,b). We found clear evidence that the shrinkage geometry varied with moisture content.

We fitted a realistic range of shrinkage geometry factors to the observed soil moisture content range and assessed the difference in $\Delta V$ for the unsaturated zone when applying $r_{\mathrm{s}}(\theta)$ values and $r_{\mathrm{s}}=\mathrm{cst}=3$ to observed vertical shrinkage. For the $r_{\mathrm{s}}(\theta)$ range used here, we found an overestimation of $\Delta V$ up to $26.4 \%(17.5 \mathrm{~mm})$ for the actively shrinking soil layer between surface level and $60 \mathrm{~cm}$ depth, when assuming constant isotropic shrinkage.

At the bulk soil scale, the structural shrinkage phase accounted for a large share of water loss of the profile. Deep layers experienced initial structural shrinkage at the upper soil at the beginning of drying, but lower parts remained wet for a long time under influence of the ground water level and the capillary fringe. At delayed drying, these lower parts also experienced structural shrinkage, while the drier upper soil experienced basic, residual or zero shrinkage, causing the net shrinkage of the entire soil profile to be less than normal. At the end of the measurement period, water loss in the structural shrinkage phase was approx. $43 \%$ of total water loss for the $0-60 \mathrm{~cm}$ layer, and up to approx. $62 \%$ for the $0-150 \mathrm{~cm}$ layer. The remainder of water loss occurred in the basic shrinkage phase. Textural layering, soil moisture content gradients, and groundwater level are therefore important factors determining total soil-profile volume change and its relation with soil water storage change.

Under variable weather conditions (many alternating wet and dry periods), both hysteresis in swelling and shrinkage and the different shrinkage phases represented in the profile simultaneously, further decreased the slopes of field shrinkage curves. Nevertheless, the $\Delta V-\Delta W$ relationship remained linear. Soil moisture measurements in soil volumes spanning multiple aggregates and cracks remained robust under these circumstances.

In order to use soil surface elevations changes as a proxy for soil water storage change in clayey soils, $r_{\mathrm{s}}$ variations with soil moisture, the effect of variable drying and wetting conditions, and the water loss in the structural shrinkage phase have to be considered, since solely relying on surface level elevation changes will lead to a large underestimation of soil water storage variations. In different wetting/drying regimes, the effective $r_{\mathrm{s}}-\theta$ relation calculated here will be affected by hysteresis between swelling and shrinkage. The effects of both processes on $\Delta V$ calculations are assessed separately in this study. In an alternating wetting and drying regime both processes are expected to be present, and the effects on $\Delta V$ calculations need to be assessed simultaneously by independent measurements.

Current and future technologies like GPS, satellite or airborne radar interferometry (InSAR), and airborne laser scanning (LIDAR) may be capable of measuring elevation changes with sufficient vertical and temporal detail on larger (field to catchment) scales (Gabriel et al., 1989; Bamler and Hartl, 1998; Gao, 2007; Te Brake et al., 2013). However, more detailed shrinkage relations have to be applied to estimate storage changes in soil profiles from these measurements. Since the slope of the relationship between $\Delta W$ and $\Delta V$ depends on the drying regime and measurement scale, direct translation of shrinkage curves obtained through conventional laboratory tests on clay aggregates needs to be applied with care; at this time it is still better to directly observe the in situ shrinkage curves rather than convert a laboratory curve to field conditions. Such field-scale swelling and shrinkage curves need only be determined once for a given location, but require determination of $r_{\mathrm{s}}(\theta)$ and weather conditions that allow the soil to go through a wide range of water contents and alternating swelling and shrinkage. The progress in theoretical conversions from laboratory shrinkage curves to field curves over the past years (e.g. Chertkov, 2005, 2012a) is promising and might provide a solution to this issue in the future. This will require the experimental determination of field shrinkage curves, and this paper might be of use in planning the required field campaigns.

Acknowledgements. The authors thank Dirk and Jan de Heer and Roland Knook for kindly permitting access to the measurement locations and for support during the field campaign. Meteorological data, except for Parsival data, were provided by the Royal Netherlands Meteorological Institute. Technical support was provided by Harm Gooren, Hennie Gertsen, and Pieter Hazenberg from Wageningen University. This research was financially supported by Netherlands Space Office (NSO) under project GO-AO/12.

Edited by: N. Romano

\section{References}

Aitchison, G. D. and Holmes, J. W.: Aspects of swelling in the soil profile, Aust. J. App. Sci., 4, 244-259, 1953.

Arya, L. M., Richter, J. C., and Paris, J. F.: Estimating profile water storage from surface zone soil-moisture measurements under bare field conditions, Water Resour. Res., 19, 403-412, 1983.

Bamler, R. and Hartl, P.: Synthetic aperture radar interferometry, Inverse Probl., 14, R1-R54, doi:10.1088/0266-5611/14/4/001, 1998.

Bogena, H. R., Huisman, J. A., Oberdoerster, C., and Vereecken, H.: Evaluation of a low-cost soil water content sensor 
for wireless network applications, J. Hydrol., 344, 32-42, doi:10.1016/j.jhydrol.2007.06.032, 2007.

Bogena, H. R., Huisman, J. A., Meier, H., Rosenbaum, U., and Weuthen, A.: Hybrid Wireless Underground Sensor Networks: Quantification of Signal Attenuation in Soil, Vadose Zone J., 8, 755-761, doi:10.2136/vzj2008.0138, 2009.

Bogena, H. R., Herbst, M., Huisman, J. A., Rosenbaum, U., Weuthen, A., and Vereecken, H.: Potential of Wireless Sensor Networks for Measuring Soil Water Content Variability, Vadose Zone J., 9, 1002-1013, doi:10.2136/vzj2009.0173, 2010.

Boivin, P.: Anisotropy, cracking, and shrinkage of vertisol samples: Experimental study and shrinkage modeling, Geoderma, 138, 25-38, 2007.

Braudeau, E. and Mohtar, R. H.: Modeling the swelling curve for packed soil aggregates using the pedostructure concept, Soil Sci. Soc. Am. J., 70, 494-502, doi:10.2136/sssaj2004.0211, 2006.

Braudeau, E., Costantini, J. M., Bellier, G., and Colleuille, H.: New device and method for soil shrinkage curve measurement and characterization, Soil Sci. Soc. Am. J., 63, 525-535, 1999.

Braudeau, E., Frangi, J. P., and Mohtar, R. H.: Characterizing nonrigid aggregated soil-water medium using its shrinkage curve, Soil Sci. Soc. Am. J., 68, 359-370, 2004.

Bridge, B. J. and Ross, P. J.: Relations among physical properties of cracking clay soils, in: Properties and Utilisation of Cracking Clay Soils, edited by: McGarity, J. W., Hoult, E. H., and So, H. B., 97-104, University of New England: Armidale, New South Wales, Australia, 1984.

Bronswijk, J. J. B.: Modeling of water balance, cracking and subsidence of clay soils, J. Hydrol., 97, 199-212, 1988.

Bronswijk, J. J. B.: Shrinkage geometry of a heavy clay soil at various stresses, Soil Sci. Soc. Am. J., 54, 1500-1502, 1990.

Bronswijk, J. J. B.: Drying, cracking, and subsidence of a clay soil in a lysimeter, Soil Sci., 152, 92-99, 1991a.

Bronswijk, J. J. B.: Relation between vertical soil movements and water-content changes in cracking clays, Soil Sci. Soc. Am. J., 55, 1220-1226, 1991b.

Bronswijk, J. J. B. and Evers-Vermeer, J. J.: Shrinkage of Dutch clay soil aggregates, Neth. J. Agr. Sci., 38, 175-194, 1990.

Brown, K. F., Messem, A. B., Dunham, R. J., and Biscoe, P. V.: Effect of drought on growth and water-use of sugar-beet, J. Agr. Sci., 109, 421-435, 1987.

Cabidoche, Y. M. and Ozier-Lafontaine, H. O.: Theresa 1: Matric water-content measurements through-thickness variations in vertisols, Agr. Water Manage., 28, 133-147, 1995.

Cabidoche, Y. M. and Voltz, M.: Nonuniform volume and watercontent changes in swelling clay soil. 2: A field-study on a vertisol., Eur. J. Soil Sci., 46, 345-355, 1995.

Camposeo, S. and Rubino, P.: Effect of irrigation frequency on root water uptake in sugar beet, Plant Soil, 253, 301-309, doi:10.1023/A:1024801312711, 2003.

Cardell-Oliver, R., Kranz, M., Smettem, K., and Mayer, K.: A reactive soil moisture sensor network: Design and field evaluation, in: International Conference on Intelligent Sensing and Sensor Networks, Melbourne, Australia, Dec, 2004, 149-162, doi:10.1080/15501320590966422, 2005.

Chertkov, V. Y.: The Shrinkage Geometry Factor of a Soil Layer, Soil Sci. Soc. Am. J., 69, 1671-1683, 2005.

Chertkov, V. Y.: The reference shrinkage curve at higher than critical soil clay content, Soil Sci. Soc. Am. J., 71, 641-655, doi:10.2136/sssaj2006.0146, 2007a.

Chertkov, V. Y.: The soil reference shrinkage curve, Open Hydrol. J., 1, 1-18, 2007b.

Chertkov, V. Y.: The geometry of soil crack networks, Open Hydrol. J., 2, 34-48, 2008.

Chertkov, V. Y.: An integrated approach to soil structure, shrinkage, and cracking in samples and layers, Geoderma, 173-174, 258273, 2012a.

Chertkov, V. Y.: Physical modeling of the soil swelling curve vs. the shrinkage curve, Adv. Water Resour., 44, 66-84, doi:10.1016/j.advwatres.2012.05.003, 2012b.

Chertkov, V. Y., Ravina, I., and Zadoenko, V.: An approach for estimating the shrinkage geometry factor at a moisture content, Soil Sci. Soc. Am. J., 68, 1807-1817, 2004.

Coquet, Y., Touma, J., and Boivin, P.: Comparison of soil linear shrinkage curve from extracted cores and in situ, Aust. J. Soil Res., 36, 765-782, 1998.

Cornelis, W. M., Corluy, J., Medina, H., Díaz, J., Hartmann, R., Van Meirvenne, M., and Ruiz, M. E.: Measuring and modelling the soil shrinkage characteristic curve, Geoderma, 137, 179-191, doi:10.1016/j.geoderma.2006.08.022, 2006.

Crow, W. T. and Ryu, D.: A new data assimilation approach for improving runoff prediction using remotely-sensed soil moisture retrievals, Hydrol. Earth Syst. Sci., 13, 1-16, doi:10.5194/hess13-1-2009, 2009.

De Bruin, H. A. R.: From Penman to Makkink, in: Evaporation and Weather, edited by Hooghart, J. C., Proceedings and information No. 39, Comm. Hydrol. Res. TNO, Den Haag, 5-30, 1987.

De Bruin, H. A. R. and Lablans, W. N.: Reference crop evapotranspiration determined with a modified Makkink equation, Hydrol. Process., 12, 1053-1062, doi:10.1002/(SICI)10991085(19980615)12:7<1053::AID-HYP639>3.0.CO;2-E, 1998.

De Vries, J. J. and Simmers, I.: Groundwater recharge: an overview of processes and challenges, Hydrogeology J., 10, 5-17, 2002.

Draper, C. S., Reichle, R. H., De Lannoy, G. J. M., and Liu, Q.: Assimilation of passive and active microwave soil moisture retrievals, Geophys. Res. Lett., 39, L04401, doi:10.1029/2011GL050655, 2012.

Eagleson, P. S.: Climate, soil, and vegetation, 6. Dynamics of the Annual Water Balance, Water Resour. Res., 14, 749-764, 1978.

Farmer, D., Sivapalan, M., and Jothityangkoon, C.: Climate, soil, and vegetation controls upon the variability of water balance in temperate and semiarid landscapes: Downward approach to water balance analysis, Water Resour. Res., 39, 1035, doi:10.1029/2001WR000328, 2003.

Feddes, R.: Crop factors in relation to Makkink's reference crop evapotranspiration, in: Evaporation and Weather, edited: by Hooghart, J. C., Proceedings and information No. 39, Comm. Hydrol. Res. TNO, Den Haag, 5-30, 1987.

Francesca, V., Osvaldo, F., Stefano, P., and Paola, R. P.: Soil Moisture Measurements: Comparison of Instrumentation Performances, J. Irrig. Drain. E-ASCE, 136, 81-89, 2010.

Gabriel, A. K., Goldstein, R. M., and Zebker, H. A.: Mapping Small Elevation Changes Over Large Areas - Differential Radar Interferometry, J. Geophys. Res.-Solid, 94, 9183-9191, doi:10.1029/JB094iB07p09183, 1989.

Gao, J.: Towards accurate determination of surface height using modern geoinformattic methods: possibilities and limitations, Prog. Phys. Geog., 31, 591-605, 
doi:10.1177/0309133307087084, 2007.

Gee, G. W. and Hillel, D.: Groundwater recharge in arid regions Review and critique of estimation methods, Hydrol. Process., 2, 255-266, 1988

Haines, W. B.: The volume-changes associated with variations of water content in soil, J. Agr. Sci., 13, 296-310, doi:10.1017/S0021859600003580, 1923.

Huisman, J. A., Hubbard, S. S., Redman, J. D., and Annan, A. P.: Measuring Soil Water Content with Ground Penetrating Radar: A Review, Vadose Zone J., 2, 476-491, 2003.

Jayawardane, N. S. and Greacen, E. L.: The nature of swelling in soils, Aust. J. Soil Res., 25, 107-113, 1987.

Kirby, J. M., Bernardi, A. L., Ringrose-Voase, A. J., Young, R., and Rose, H.: Field swelling, shrinking, and water content change in a heavy clay soil, Aust. J. Soil Res., 41, 963-978, 2003.

KNMI: available at: http://www.knmi.nl, last access: 27 February 2013.

Lievens, H., Verhoest, N. E. C., De Keyser, E., Vernieuwe, H., Matgen, P., Álvarez-Mozos, J., and De Baets, B.: Effective roughness modelling as a tool for soil moisture retrieval from C- and L-band SAR, Hydrol. Earth Syst. Sci., 15, 151-162, doi:10.5194/hess15-151-2011, 2011.

Liu, Q., Reichle, R. H., Bindlish, R., Cosh, M. H., Crow, W. T., de Jeu, R., De Lannoy, G. J. M., Huffman, G. J., and Jackson, T. J.: The Contributions of Precipitation and Soil Moisture Observations to the Skill of Soil Moisture Estimates in a Land Data Assimilation System, J. Meteorol, 12, 750-765, doi:10.1175/JHM-D-10-05000.1, 2011.

Logsdon, S. D.: CS616 Calibration: Field versus Laboratory, Soil Sci. Soc. Am. J., 73, 1-6, doi:10.2136/sssaj2008.0146, 2009.

Milly, P. C. D.: Climate, interseasonal storage of soil-water, and the annual water-balance, Adv. Water Resour., 17, 19-24, 1994.

Milly, P. C. D. and Dunne, K. A.: Sensitivity of the global water cycle to the water holding capacity of land, J. Climate, 7, 506526, 1994.

Mitchell, A. R.: Soil surface shrinkage to estimate profile soil-water, Irrigation Sci., 12, 1-6, 1991.

Mitchell, A. R. and Van Genuchten, M. T.: Shrinkage of bare and cultivated soil, Soil Sci. Soc. Am. J., 56, 1036-1042, 1992.

Parsons, L. R. and Bandaranayake, W. M.: Performance of a New Capacitance Soil Moisture Probe in a Sandy Soil, Soil Sci. Soc. Am. J., 73, 1378-1385, doi:10.2136/sssaj2008.0264, 2009.

Peng, X. and Horn, R.: Anisotropic shrinkage and swelling of some organic and inorganic soils, Eur. J. Soil Sci., 58, 98-107, doi:10.1111/j.1365-2389.2006.00808.x, 2007.

Rijniersce, K.: A simulation model for physical soil ripening in the IJsselmeerpolders, Flevobericht No.233, Rijksdienst voor de IJsselmeerpolders, Lelystad, 1983.
Robinson, D. A., Campbell, C. S., Hopmans, J. W., Hornbuckle, B. K., Jones, S. B., Knight, R., Ogden, F., Selker, J., and Wendroth, O.: Soil moisture measurement for ecological and hydrological watershed-scale observatories: A review, Vadose Zone J., 7, 358-389, doi:10.2136/vzj2007.0143, 2008.

Sakaki, T., Limsuwat, A., Smits, K. M., and Illangasekare, T. H.: Empirical two-point alpha-mixing model for calibrating the ECH2O EC-5 soil moisture sensor in sands, Water Resour. Res., 44, 526-531, doi:10.1029/2008WR006870, 2008.

Soil Survey Staff: Keys to Soil Taxonomy, USDA-Natural Resources Conservation Service, Washington, DC., 11th Edn., 2010.

Stirk, G. B.: Some aspects of soil shrinkage and the effect of cracking upon water entry into the soil, Aust. J. Agr. Res., 5, 279-290, 1954.

Te Brake, B., Hanssen, R. F., Van der Ploeg, M. J., and De Rooij, G. H.: Satellite based radar interferometry to estimate large-scale soil water depletion from clay shrinkage: possibilities and limitations, Vadose Zone J., doi:10.2136/vzj2012.0098, in press, 2013.

Vereecken, H., Huisman, J. A., Bogena, H., Vanderborght, J., Vrugt, J. A., and Hopmans, J. W.: On the value of soil moisture measurements in vadose zone hydrology: A review, Water Resour. Res., 44, W00D06, doi:10.1029/2008WR006829, 2008.

Walker, J. P., Willgoose, G. R., and Kalma, J. D.: One-dimensional soil moisture profile retrieval by assimilation of near-surface observations: a comparison of retrieval algorithms, Adv. Water Resour., 24, 631-650, doi:10.1016/S0309-1708(00)00043-9, 2001.

Western, A. W., Grayson, R. B., and Green, T. R.: The Tarrawarra project: High resolution spatial measurement, modelling and analysis of soil moisture and hydrological response, Hydrol. Process., 13, 633-652, 1999.

Yang, J., Zhang, C., Li, X., Huang, Y., Fu, S., and Acevedo, M. F.: Integration of wireless sensor networks in environmental monitoring cyber infrastructure, Wirel Netw, 16, 1091-1108, doi:10.1007/s11276-009-0190-1, 2010.

Yule, D. F. and Ritchie, J. T.: Soil Shrinkage Relationships of Texas Vertisols: 1. Small Cores, Soil Sci. Soc. Am. J., 44, 1285-1291, 1980a.

Yule, D. F. and Ritchie, J. T.: Soil Shrinkage Relationships of Texas Vertisols: 2. Large Cores, Soil Sci. Soc. Am. J., 44, 1291-1295, 1980b.

Yuter, S. E., Kingsmill, D. E., Nance, L. B., and Loeffler-Mang, M.: Observations of precipitation size and fall speed characteristics within coexisting rain and wet snow, J. Appl. Meteorol. Clim., 45, 1450-1464, doi:10.1175/JAM2406.1, 2006.

Zhang, R. B., Guo, J. J., Zhang, L., Zhang, Y.-C., Wang, L. H., and Wang, Q.: A calibration method of detecting soil water content based on the information-sharing in wireless sensor network, Comput. Electron. Agr., 76, 161-168, doi:10.1016/j.compag.2011.01.010, 2011. 